\title{
Experiments and calculations of cnoidal wave loads on a flat plate in shallow-water
}

\author{
Masoud Hayatdavoodi • Betsy Seiffert • \\ R. Cengiz Ertekin
}

Received: 27 April 2014 / Accepted: 22 October 2014 / Published online: 13 November 2014

(C) Springer International Publishing AG 2014

\begin{abstract}
Horizontal and vertical wave forces due to the interaction of cnoidal waves with a two-dimensional, horizontal flat plate located in shallow-water are studied through laboratory experiments and calculations. The experiments are conducted for a combination of two water depths, five wavelengths and four wave heights, corresponding to the propagation of nonlinear waves in shallow-water depth. The model is located at six different elevations and submergence depths such that all possible cases of a coastal bridge deck fully above the still-water level, a deck on the surface and a fully submerged deck are considered in the study. Calculations are performed for the same cases as in the laboratory experiments and include the results of a nonlinear shallowwater wave model based on the Level I Green-Naghdi equations for the fully submerged cases, and Euler's equations coupled with the Volume of Fluid interface tracking method for one submerged case, one elevated case, and one case at the water surface. Comparison of existing theoretical solutions are also provided, including the Long-Wave Approximation based on linear potential theory for the submerged cases, and empirical relations for the elevated cases. The set of data presented here provides an insight into storm wave loads on the decks of coastal bridges, jetties and piers located in shallowwater areas.
\end{abstract}

\footnotetext{
M. Hayatdavoodi $(\varangle)$

Department of Maritime Systems Engineering, Texas

A\&M University, Galveston, TX 77554, USA

e-mail: masoud@tamu.edu

B. Seiffert · R. C. Ertekin

Department of Ocean and Resources Engineering,

University of Hawaii, Honolulu, HI 96822, USA
}

Keywords Cnoidal wave forces $\cdot$ Laboratory experiments . OpenFOAM · Green-Naghdi equations · Bridge deck · Flat plate

\section{Introduction}

During a hurricane event, storm surge and wind-induced waves are known to be the primary agents of failure of coastal bridges. As a result of storm surge, larger waves may impinge on coastal bridges, normally located above the wave crest. The wave-induced loads on the decks of coastal bridges have a vertical and a horizontal component. Failure occurs if the wave-induced loads exceed the capacity of the structure in any of these directions. Examples of such failures were observed during Hurricanes Ivan and Katrina. Further information on major bridge failures during Hurricane Katrina, for example, can be found in Des Roches (2006), Robertson et al. (2007), Padgett et al. (2008) and Chen et al. (2009). Such failure is not limited to coastal bridge decks, but also observed in jetties, piers and docks with a horizontal deck.

In addition to the wave-induced forces, the storm surge may be such that the bridge deck becomes fully inundated, which, for example, occurred along the damaged portions of the US90 Bridge over Biloxi Bay during Hurricane Katrina, as reported by Chen et al. (2009). Although waves would propagate on the top of the deck and on the surface, the buoyancy force acts on the submerged deck in favor of the destructive forces, and failure may occur during this stage.

Until very recently, only a few laboratory experiments and empirical relations have focused on the topic of wave forces on the decks of coastal bridges. Existing laboratory experiments on the interaction of periodic waves with a horizontal 
flat deck (or simply flat plate) include the works of Brater et al. (1958), El Ghamry (1963), French (1969), Wang (1970), Denson (1978), Bhat (1994), Shih and Anastasiou (1992), Tirindelli et al. (2002), McPherson (2008), and more recently Schumacher et al. (2008). Laboratory experiments on solitary wave forces were recently conducted by Seiffert et al. (2014) and Lo and Liu (2014) for a flat plate, and by Hayatdavoodi et al. (2014) for a plate with girders.

Due to the complexities associated with the problem of interaction of nonlinear waves with an elevated deck or a deck on the free surface, theoretical studies mainly include empirical relations which are developed by conducting laboratory experiments or expanding some existing empirical relations [such as the equation of Morison et al. (1950)]. These include the empirical relations given by Wang (1970), Kaplan et al. (1995), Bea et al. (1999), Douglass et al. (2006) and McPherson (2008). Aside from the empirical relations, Baarholm and Faltinsen (2004) and Meng (2008) used linear potential theory, subjected to appropriate boundary conditions, to estimate the wave loads on an elevated deck. Wave loads on specific prototype bridge decks are calculated by Meng (2008) and Huang and Xiao (2009) by solving the Reynolds-Averaged Navier-Stokes (RANS) equations utilizing a computational fluid dynamics approach. Recently, solitary wave forces on a flat plate were calculated by Seiffert et al. (2014), by solving Euler's equations through the CFD software OpenFOAM.

For a fully submerged deck, Siew and Hurley (1977) considered a thin flat plate and solved the Laplace equation, assuming linear long-wave conditions, to determine the velocity potential. The final form of the wave forces were given later by Patarapanich (1984a). This theory is known as the Long-Wave Approximation. Recently, Hayatdavoodi and Ertekin (2012) and Hayatdavoodi and Ertekin (2014b) used the nonlinear shallow-water Level I Green-Naghdi (GN) equations to solve the problem of nonlinear wave loads on a fully submerged plate in shallow-water.

Although these experiments and theoretical approaches provide an insight into the periodic wave loads on a flat plate, with the exception of the work of Hayatdavoodi and Ertekin (2014c), none of them considers nonlinear wave conditions that are applicable to coastal structures located in shallowwater. Most of the structures that are considered here are located in shallow-water, where long waves may interact with the structures. It is, therefore, of great interest to consider the extreme conditions that may result in structural failure. Also, except for the experiments of Brater et al. (1958), none of the experiments have considered wave loads on a fully submerged deck.

In this study, the results of a series of laboratory experiments on the interaction of cnoidal waves with a rigid and fixed horizontal deck located in shallow-water are presented. A combination of two water depths, five wavelengths, four wave heights and six submergence depths or elevation heights from the still-water level (SWL) are considered, covering a wide range of possible conditions of storm wave interaction with a deck located in shallow-water. We will calculate the cnoidal wave loads on a horizontal flat plate by solving Euler's equations, as was done by Seiffert et al. (2014) and Hayatdavoodi et al. (2014), the Level I Green-Naghdi nonlinear equations developed by Hayatdavoodi and Ertekin (2014b), the linear Long-Wave Approximation of Siew and Hurley (1977), and two empirical relations introduced by Douglass et al. (2006) and McPherson (2008).

During the laboratory experiments measuring periodic wave loads on an elevated flat plate conducted by Shih and Anastasiou (1992), it was observed that even for the same incoming wave, the recorded impact force on the plate varies when the experiments are repeated. Such randomness was explained as a result of the irregular nature of the wave breaking process and possibly trapped air pockets underneath the plate. The Rayleigh probability density distribution was used to explain a possible pattern for the wave loads. Such irregular behavior is also observed in the current study. However, we are only interested in those results (vertical and horizontal forces) that are repeatable, which can be used directly by design engineers or to assess the vulnerability of coastal structures to storm waves. We avoid such probabilistic studies of the force representation and do not present any results that are not experimentally repeatable within a given error bound that will be discussed.

The main goal of this work is to present the laboratory measurements and calculations of vertical and horizontal forces due to cnoidal waves on a flat plate located in shallowwater. The experimental data are compared with both numerical calculations and empirical results. The experimental design is introduced in Sect. 2, and the theories used in the numerical calculations and empirical estimations are discussed in Sect. 3. Results are presented in three subsections for an elevated plate, a plate on the surface, and a submerged plate in Sect. 4. The paper is closed with some concluding remarks in Sect. 5.

\section{Experimental design}

\subsection{Facilities and instrumentation}

Experiments are carried out at the University of Hawaii at Manoa's Hydraulics Laboratory in the Civil and Environmental Engineering Department. The wave flume measures $9.14 \mathrm{~m}$ length, $15.24 \mathrm{~cm}$ width, and $15.5 \mathrm{~cm}$ height and waves are generated by a piston-type wavemaker. Parabolic shaped foam wave absorbers manufactured by H. R. Wallingford are placed at each end of the wave flume, one as an absorbing beach and one to absorb reflections behind the wavemaker. 
Three capacitance-type wave gauges measure surface elevation with a spatial resolution of $0.1 \mathrm{~mm}$ and sampling rate of $71 \mathrm{~Hz}$ (manufactured by JFE Advantech Co., Ltd). Horizontal forces are measured using three $44.5 \mathrm{~N}$ load cells and vertical forces are measured using one $44.5 \mathrm{~N}$ load cell. Horizontal force is obtained by adding measurements from the three horizontal load cells at each time step, whereas the vertical force is obtained directly from the vertical load cell measurements. The load cells have a resolution of $0.022 \mathrm{~N}$ and force is sampled at $100 \mathrm{~Hz}$. Air and fresh-water temperature were measured at $20^{\circ} \mathrm{C}$.

\subsection{Model specimen and setup}

A clear acrylic horizontal plate with length $L_{\mathrm{P}}=14.9 \mathrm{~cm}$, width $B=30.5 \mathrm{~cm}$, and thickness $t_{\mathrm{P}}=1.27 \mathrm{~cm}$ is used, where length is defined in the direction parallel to wave propagation and width is defined as the direction perpendicular to wave propagation (Fig. 1). This plate could represent, for example, a simplified version of a typical two-lane coastal bridge of width $10.675 \mathrm{~m}$ at a 1:35 scale. The plate is attached to an aerodynamically shaped vertical aluminum strut which is attached to a rigid support structure constructed of unistrut by three horizontal load cells (two at $43.2 \mathrm{~cm}$ and one $68.6 \mathrm{~cm}$ elevations above the plate) and one vertical load cell (at $77.0 \mathrm{~cm}$ elevation above the plate), seen in Figs. 1 and 2.

The model is placed in the flume at a distance of $5.22 \mathrm{~m}$ from the end of the tank and $2.62 \mathrm{~m}$ from the wavemaker (Fig. 3). Wave gauges are positioned two plate widths (WG1) and one plate width (WG2) upwave of the leading edge of the plate and two plate widths downwave of the trailing edge

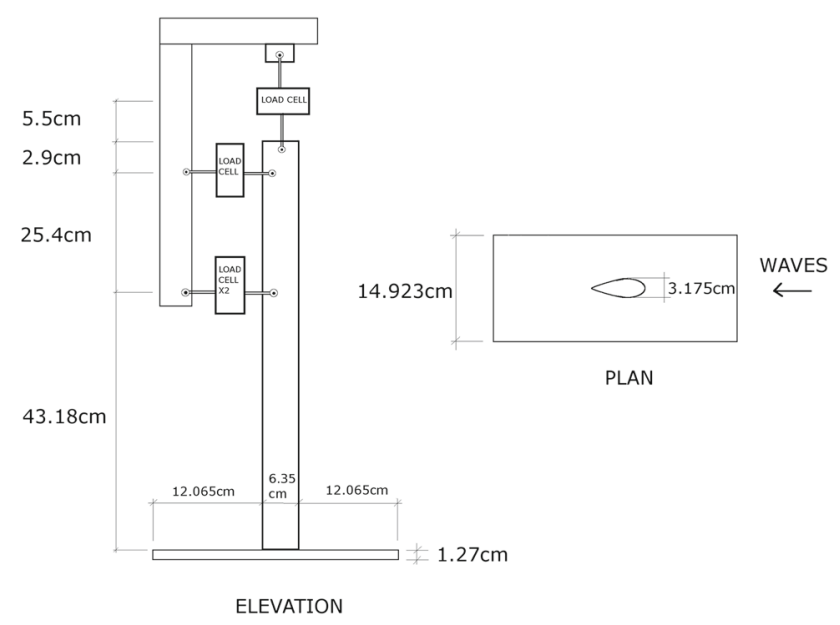

Fig. 1 A clear acrylic horizontal plate is attached to a vertical aerodynamically shaped aluminum strut. The strut is affixed to the mounting by four $44.5 \mathrm{~N}$ load cells. Vertical force is measured by the uppermost load cell while horizontal force is calculated by adding measurements from the middle and two lower load cells (one is behind the other). Not to scale

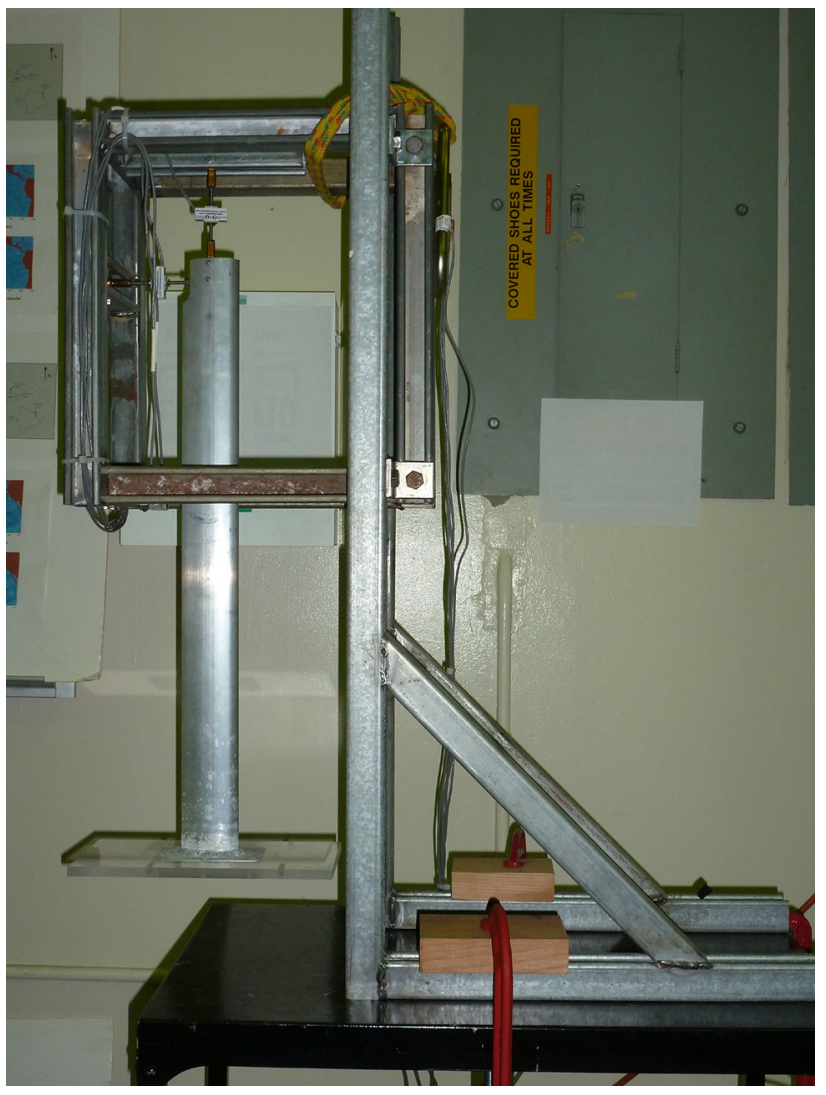

Fig. 2 The plate and strut are affixed to a rigid support structure that is positioned in the tank $2.62 \mathrm{~m}$ from the wavemaker and $5.22 \mathrm{~m}$ from the end of the tank

of the plate (WG3). Wave gauge measurements in the presence of the plate are used for comparison with calculations. Measurements are also taken with WG2 placed at the location of the leading edge of the plate without the plate present to measure the incoming wave height and period, and this is discussed in Sect. 2.3.

\subsection{Test procedure}

Wave heights and periods were chosen to cover a range of nonlinear shallow-water to shallower to intermediate-water waves characterized by cnoidal wave theory as suggested by, for example, Sarpkaya and Isaacson (1981), to cover a range of realistic prototype conditions that may occur during a storm event. Table 1 contains a list of tested water depths $(h)$, wave heights $(H)$, wavelengths $(\lambda)$, and periods $(T)$, and corresponding prototype conditions. Each wave height and period was tested for dimensionless submergence depths of $z / h=0.0,0.2,0.4$ and 0.6 (where $z$ is measured from the SWL to the top of the plate) and elevations of $z^{*} / h=0.06$ and 0.1 (where $z^{*}$ is measured from the SWL to the bottom of the plate). The same wave parameters and submergence depths and elevations were tested on the strut alone to deter- 
Fig. 3 Wave gauges are positioned two plate widths $(W G 1)$ and one plate width (WG2) upwave of the leading edge of the plate and two plate widths downwave of the trailing edge of the plate (WG3). Not to scale

Table 1 A range of wave heights and wavelengths are tested according to a realistic range of prototype conditions that may occur during a storm

All units are in meters unless otherwise specified

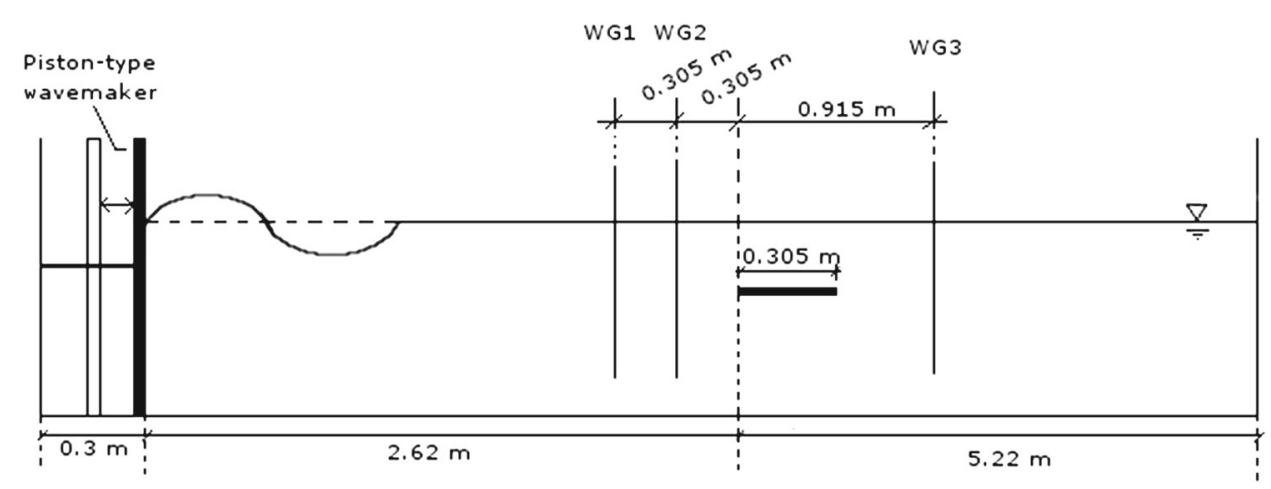

\begin{tabular}{lll}
\hline Test parameter & Model $(1: 35)$ & Prototype $(1: 1)$ \\
\hline Water depth $(h)$ & $0.071,0.114$ & $2.5,4$ \\
Wave height $(H)$ & & \\
$\quad h=0.071$ & $0.007,0.014,0.021,0.028$ & $0.25,0.5,0.75,1$ \\
$\quad h=0.114$ & $0.011,0.023,0.034,0.046$ & $0.4,0.8,1.2,1.6$ \\
Wavelength $(\lambda)$ & $1.4,1.7,1.9,2.1,2.3$ & $49.0,59.5,66.5,73.5,80.5$ \\
Wave period $(T)$ & & \\
$h=0.071$ & $1.58-2.71 \mathrm{~s}$ & $9.347-16.033 \mathrm{~s}$ \\
$h=0.114$ & $1.32-2.18 \mathrm{~s}$ & $7.809-12.897 \mathrm{~s}$ \\
\hline
\end{tabular}

mine contributions due to the strut on the measured horizontal forces. The average positive and negative forces measured on the strut were then subtracted from the final positive and negative force measurements on the model to find the final horizontal force measurements.

\subsection{Wave generation}

Paddle motion of the piston-type wavemaker is controlled by the LabVIEW software and is dictated by an input timevelocity displacement series. The time-velocity displacement series is generated following a method outlined by Goring (1979) to solve for paddle displacement and initial stroke position using the solution for water surface elevation $(\eta)$ for shallow-water waves. In these experiments, we use the solution of the Level I GN equations for surface elevation of a cnoidal wave given by Sun (1991) and Ertekin and Becker (1998). In dimensional form, it is

$\eta=\eta_{2}+H \mathrm{cn}^{2}\{\theta, m\}$,

where

$$
\begin{aligned}
\theta & =2 K\left(\frac{x_{1}}{\lambda}-\frac{t}{T}\right), \\
c^{2} & =g h\left(1+\frac{\eta_{1}}{h}\right)\left(1+\frac{\eta_{2}}{h}\right)\left(1+\frac{\eta_{3}}{h}\right), \\
\eta_{1} & =-\frac{H E}{m K},
\end{aligned}
$$

$$
\begin{aligned}
& \eta_{2}=\frac{H}{m}\left(1-m-\frac{E}{K}\right), \\
& \eta_{3}=\frac{H}{m}\left(1-\frac{E}{K}\right),
\end{aligned}
$$

and the dispersion relation is given by

$H \lambda^{2}=\frac{16}{3}\left(\frac{c^{2} h^{2}}{g}\right) m K^{2}$,

where $H$ is the wave height, $m$ is the Jacobian elliptic parameter, $\mathrm{cn}$ is the Jacobian elliptic function, $\theta$ is the argument, $K(m)$ is the first complete elliptic integral, $E(m)$ is the second complete elliptic integral, $c$ is the wave phase speed, $x_{1}$ is displacement in the direction of wave propagation, $\lambda$ is the wavelength, $t$ is time, $T$ is wave period, $h$ is water depth, and $g$ is gravitational acceleration. The dispersion relation is used to solve for the implicit parameter $m$ using the NewtonRaphson method.

\subsection{Experimental measurements}

Force and surface elevation measurements are taken such that the initial wave has passed the model location but has not been reflected back, leaving 2-3 waves for analysis, depending on the wavelength. Each case (where one case is one water depth, one wavelength, one wave height and one submergence depth or elevation) is repeated three times so that there 

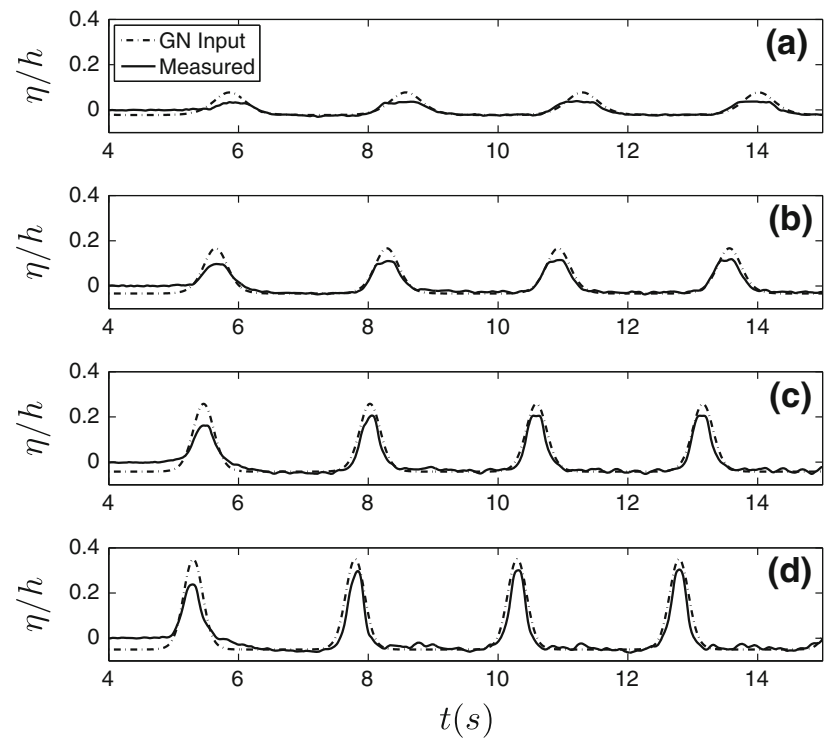

Fig. 4 Measured non-dimensional surface elevation $(\eta / h)$ is compared with the GN equations surface elevation input at the wavemaker for $h=0.071 \mathrm{~m}, T=2.3 \mathrm{~s}$ and wave heights $H / h=0.1,0.2,0.3,0.4$ shown in (a), (b), (c), and (d), respectively

are 6-9 surface elevation and force measurements for each case. The maxima and minima measurements are removed and the presented results are an average of the remaining measurements and have a standard deviation within $\pm 5.5 \%$ error from the mean. For example, not all data points in Figs. 14 and 15 are presented due to larger repeatability errors.

Waves are measured at the location of the leading edge of the plate without the plate present to measure the incoming wave height and period and determine the repeatability of the generated waves. Figure 4 shows the results for measured surface elevation versus predicted surface elevation based on the GN theory for $h=0.071 \mathrm{~m}, T=2.3 \mathrm{~s}$ and dimensionless wave heights $H / h=0.1,0.2,0.3,0.4$. Measurements for wave height and period agree well with those predicted by the GN equations, with some wave attenuation evident in the smaller than predicted wave heights seen at each $H / h$. Input wavelength ( $\left.\lambda_{\text {input }}\right)$ and wave height ( $\left.H / h_{\text {input }}\right)$ are used to calculate the target wave period $\left(T_{\text {calc }}\right)$ using the GN theory. Wave period and wave height are measured at the location of the model ( $T_{\text {meas }}$ and $\left.H / h_{\text {meas }}\right)$ and then the wavelength is calculated from these measured values using the GN theory $\left(\lambda_{\text {calc }}\right)$. A list of these results is found in Tables 2 and 3, for $h=0.071 \mathrm{~m}$ and $h=0.114 \mathrm{~m}$ water depths, respectively. The percent difference between the measurements is well within $\pm 5 \%$ and the average repeatability error for the wave period is 0.32 and $0.46 \%$, and for the wave height it is 1.02 and $0.64 \%$ for the water depths $h=0.071 \mathrm{~m}$ and $h=0.114 \mathrm{~m}$, respectively.
A cubic spline method is applied to the force data using the MATLAB function "csaps" with a chosen smoothing parameter that best reduces structural vibrations and noise while preserving the maximum and minimum force peaks. Small magnitude, high-frequency oscillations in the data are attributed to vibrations along the flume walls due to the movement of the wavemaker and the natural frequency of the model, which has previously been measured at approximately $25 \mathrm{~Hz}$ in the horizontal direction and $50 \mathrm{~Hz}$ in the vertical direction for the same model specimen with attached girders. As the attached girders add nominal weight to the structure, we make the assumption that these frequencies will remain approximately the same. For the submerged cases, smoothing parameters of $p=0.99999$ and $p=0.9999$ are applied to vertical and horizontal forces, respectively, and smoothing parameters of $p=0.999999$ and $p=0.99999$ are applied to vertical and horizontal forces, respectively, for the elevated cases. The higher smoothing parameter is chosen for elevated cases to capture any shorter duration forces on the model. Once smoothed, maximum and minimum peaks are determined. Further discussion on the effects of the smoothing parameter can be found in Hayatdavoodi et al. (2014).

\section{Theories}

In this section, we introduce four different approaches utilized here to determine the wave loads on a submerged or elevated horizontal deck. These include the Level I GreenNaghdi (nonlinear) model and the Long-Wave Approximation (linear) model for a fully submerged deck, the empirical relations for a fully elevated model, and Euler's equations coupled with the Volume of Fluid (VOF) interface capturing model for submerged or elevated decks. The rigid twodimensional deck is fixed and horizontal in all cases considered here.

\subsection{The Level I Green-Naghdi equations}

Recently, Hayatdavoodi and Ertekin (2014b) developed a nonlinear shallow-water model based on the Level I GN equations to calculate the horizontal and vertical wave forces and overturning moment on a fully submerged flat plate located in water of finite depth. Results of the GN model were compared with existing laboratory measurements of solitary and periodic waves and showed a close agreement, see also Hayatdavoodi (2013) and Hayatdavoodi and Ertekin (2014a).

The GN equations for propagation of nonlinear water waves are originally developed based on the theory of directed fluid sheets by Green and Naghdi (1974, 1976b). In this theory, the fluid is assumed to be incompressible and 
Table 2 Target wave period is calculated from input wavelength and wave height for water depth $h=0.071 \mathrm{~m}$

\begin{tabular}{|c|c|c|c|c|c|c|}
\hline$\lambda_{\text {input }}(\mathrm{m})$ & $T_{\text {calc }}(\mathrm{s})$ & $(H / h)_{\text {input }}$ & $T_{\text {meas }}(\mathrm{s})$ & $\lambda_{\text {calc }}(\mathrm{m})$ & $(\lambda / B)_{\text {calc }}$ & $(H / h)_{\text {meas }}$ \\
\hline \multirow[t]{4}{*}{1.4} & 1.684 & 0.1 & 1.684 & 1.386 & 4.546 & 0.065 \\
\hline & 1.650 & 0.2 & 1.648 & 1.381 & 4.530 & 0.155 \\
\hline & 1.614 & 0.3 & 1.614 & 1.381 & 4.531 & 0.255 \\
\hline & 1.580 & 0.4 & 1.579 & 1.383 & 4.537 & 0.364 \\
\hline \multirow[t]{4}{*}{1.7} & 2.026 & 0.1 & 2.038 & 1.695 & 5.562 & 0.073 \\
\hline & 1.978 & 0.2 & 1.985 & 1.682 & 5.519 & 0.155 \\
\hline & 1.929 & 0.3 & 1.933 & 1.680 & 5.511 & 0.258 \\
\hline & 1.883 & 0.4 & 1.885 & 1.685 & 5.527 & 0.371 \\
\hline \multirow[t]{4}{*}{1.9} & 2.254 & 0.1 & 2.260 & 1.887 & 6.192 & 0.073 \\
\hline & 2.196 & 0.2 & 2.200 & 1.888 & 6.160 & 0.160 \\
\hline & 2.139 & 0.3 & 2.145 & 1.882 & 6.174 & 0.260 \\
\hline & 2.086 & 0.4 & 2.085 & 1.874 & 6.149 & 0.360 \\
\hline \multirow[t]{4}{*}{2.1} & 2.482 & 0.1 & 2.478 & 2.073 & 6.800 & 0.068 \\
\hline & 2.414 & 0.2 & 2.418 & 2.070 & 6.792 & 0.156 \\
\hline & 2.349 & 0.3 & 2.348 & 2.072 & 6.797 & 0.264 \\
\hline & 2.288 & 0.4 & 2.293 & 2.075 & 6.807 & 0.358 \\
\hline \multirow[t]{4}{*}{2.3} & 2.710 & 0.1 & 2.705 & 2.266 & 7.434 & 0.063 \\
\hline & 2.633 & 0.2 & 2.625 & 2.250 & 7.380 & 0.146 \\
\hline & 2.558 & 0.3 & 2.563 & 2.270 & 7.444 & 0.257 \\
\hline & 2.490 & 0.4 & 2.480 & 2.258 & 7.407 & 0.359 \\
\hline
\end{tabular}

Wave period and wave height are measured at the location of the model and final wavelength is calculated using these measured values

Table 3 Target wave period is calculated from input wavelength and wave height for water depth $h=0.114 \mathrm{~m}$

\begin{tabular}{|c|c|c|c|c|c|c|}
\hline$\lambda_{\text {input }}(\mathrm{m})$ & $T_{\text {calc }}(\mathrm{s})$ & $(H / h)_{\text {input }}$ & $T_{\text {meas }}(\mathrm{s})$ & $\lambda_{\text {calc }}(\mathrm{m})$ & $(\lambda / B)_{\text {calc }}$ & $(H / h)_{\text {meas }}$ \\
\hline \multirow[t]{4}{*}{1.4} & 1.374 & 0.1 & 1.380 & 1.403 & 4.603 & 0.074 \\
\hline & 1.361 & 0.2 & 1.361 & 1.395 & 4.577 & 0.173 \\
\hline & 1.344 & 0.3 & 1.340 & 1.399 & 4.588 & 0.275 \\
\hline & 1.325 & 0.4 & 1.327 & 1.393 & 4.571 & 0.393 \\
\hline \multirow[t]{4}{*}{1.7} & 1.643 & 0.1 & 1.653 & 1.705 & 5.592 & 0.077 \\
\hline & 1.620 & 0.2 & 1.623 & 1.695 & 5.560 & 0.177 \\
\hline & 1.593 & 0.3 & 1.598 & 1.697 & 5.557 & 0.279 \\
\hline & 1.566 & 0.4 & 1.575 & 1.710 & 5.561 & 0.401 \\
\hline \multirow[t]{4}{*}{1.9} & 1.823 & 0.1 & 1.833 & 1.904 & 6.246 & 0.082 \\
\hline & 1.793 & 0.2 & 1.803 & 1.902 & 6.240 & 0.181 \\
\hline & 1.760 & 0.3 & 1.775 & 1.910 & 6.265 & 0.282 \\
\hline & 1.726 & 0.4 & 1.735 & 1.906 & 6.252 & 0.391 \\
\hline \multirow[t]{4}{*}{2.1} & 2.004 & 0.1 & 1.998 & 2.083 & 6.832 & 0.072 \\
\hline & 1.966 & 0.2 & 1.965 & 2.083 & 6.835 & 0.171 \\
\hline & 1.926 & 0.3 & 1.928 & 2.087 & 6.847 & 0.272 \\
\hline & 1.887 & 0.4 & 1.890 & 2.101 & 6.891 & 0.396 \\
\hline \multirow[t]{4}{*}{2.3} & 2.184 & 0.1 & 2.175 & 2.276 & 7.467 & 0.070 \\
\hline & 2.139 & 0.2 & 2.125 & 2.265 & 7.430 & 0.168 \\
\hline & 2.092 & 0.3 & 2.090 & 2.281 & 7.482 & 0.273 \\
\hline & 2.047 & 0.4 & 2.038 & 2.280 & 7.480 & 0.388 \\
\hline
\end{tabular}

Wave period and wave height are measured at the location of the model and final wavelength is calculated using these measured values 
inviscid, although viscosity of the fluid is not a constraint in the general form of the theory. No assumption of irrotationality of the flow is made, even though such assumption may be made to develop a specialized form of the equations, known as the Irrotational Green-Naghdi (IGN) equations, see Kim and Ertekin (2000) and Kim et al. (2001).

In the GN equations, the distribution of the vertical particle velocity is prescribed, and it defines the level of the theory. That is, the GN equations are a hierarchy of equations with each increasing level corresponding to a higher level of definition of the particle velocities. In the Level I GN equations, for example, the vertical velocity is assumed to vary linearly, which in return results in a constant horizontal velocity along the water column. With these assumptions, Green and Naghdi (1976a) developed a theory based on the theory of directed fluid sheets that satisfies the seafloor, body, and free surface boundary conditions exactly, and postulated the integrated form of the mass and momentum conservation equations. The final form of the Level I GN nonlinear shallow-water wave equations were first given by Ertekin (1984) who named them "the Green-Naghdi equations":

$$
\begin{aligned}
\eta_{, t}+\{(h+\eta-\alpha) u\}_{, x_{1}}=0, & \\
\dot{u}+g \eta_{, x_{1}}+\frac{\hat{p}, x_{1}}{\rho}= & -\frac{1}{6}\left\{[2 \eta+\alpha]_{, x_{1}} \ddot{\alpha}+[4 \eta-\alpha]_{, x_{1}} \ddot{\eta}\right. \\
& \left.+(h+\eta-\alpha)[\ddot{\alpha}+2 \ddot{\eta}]_{, x_{1}}\right\},
\end{aligned}
$$

where $\eta\left(x_{1}, t\right)$ is the surface elevation measured from the SWL, $u\left(x_{1}, t\right)$ is the horizontal particle velocity, $\hat{p}\left(x_{1}, t\right)$ is the pressure on the top surface of the fluid sheet, $\alpha\left(x_{1}\right)$ is the bottom surface of the fluid sheet and $h$ is the water depth. The fluid is assumed homogenous with constant mass density $(\rho)$, and is subject to constant gravitational acceleration $g$. The superposed dot in (4a) denotes the two-dimensional material time derivative and the double dot is defined as the second material time derivative. All lower case latin subscripts after a comma designate partial differentiation with respect to the indicated variables. In two dimensions, the motion of the fluid sheet is restricted to the $x_{1}-x_{3}$ plane in the rectangular Cartesian coordinate system $\left(x_{1}, x_{3}\right)$.

In more recent years, the higher-Level GN equations, as derived by Webster et al. (2011), are used to solve some nonlinear problems, see e.g. Zhao et al. (2014).

In the context of applying the GN equations to the problem of wave propagation over a fully submerged plate, Hayatdavoodi and Ertekin (2014b) assumed a thin plate and divided the continuous domain into four separate regions, namely upwave and downwave, and above and below the plate. In this approach, the plate is considered to be thin, in fact to have zero thickness, assuming that the thickness of the plate is much smaller than the width of the model and the water depth. The GN equations, specific to each region, are then solved simultaneously, and a uniform solution throughout the domain is obtained by use of the appropriate jump and matching conditions at the discontinuity curves. The governing equations, vertical particle velocity $\left(v_{3}\right)$, integrated pressure $(P)$ and the bottom surface pressure $(\bar{p})$ are given by

$\eta_{, t}+\{(h+\eta) u\}_{, x_{1}}=0$,

$\dot{u}+g \eta_{, x_{1}}=-\frac{1}{3}\left\{\left(2 \eta_{, x_{1}} \ddot{\eta}\right)+(h+\eta) \ddot{\eta}_{, x_{1}}\right\}$,

$v_{3}=\frac{x_{3}}{(h+\eta)} \dot{\eta}$,

$P=\left(\frac{\rho}{6}\right)(h+\eta)^{2}(2 \ddot{\eta}+3 g)$,

$\bar{p}=\left(\frac{\rho}{2}\right)(h+\eta)(\ddot{\eta}+2 g)$,

where $h=h_{\mathrm{I}}$ is the constant water depth, in upwave and downwave regions, and $h=h_{\mathrm{II}}$ is the submergence depth, in the region above the plate. The submergence depth is defined as the distance from the SWL to the top of the plate. In the region underneath the plate, the unknown top pressure and the horizontal velocity are given by

$$
\begin{gathered}
\hat{p}\left(X_{\mathrm{III}}, t\right)=\left(\frac{\hat{p}\left(X_{\mathrm{T}}, t\right)-\hat{p}\left(X_{\mathrm{L}}, t\right)}{X_{\mathrm{T}}-X_{\mathrm{L}}}\right) X_{\mathrm{III}}+\hat{p}\left(X_{\mathrm{L}}, t\right), \\
X_{\mathrm{L}} \leq X_{\mathrm{III}} \leq X_{\mathrm{T}}, \\
u\left(x_{1}, t\right)=u(t)=-\rho \int \hat{p}_{, x_{1}}(t) \mathrm{d} t, \quad X_{\mathrm{L}}<x_{1}<X_{\mathrm{T}},
\end{gathered}
$$

where $X_{\mathrm{L}}$ and $X_{\mathrm{T}}$ are the longitudinal coordinate of the leading and trailing edges of the plate, respectively. $\hat{p}\left(X_{\mathrm{L}}, t\right)$ and $\hat{p}\left(X_{\mathrm{T}}, t\right)$ are the top pressures of the fluid sheet in the region underneath the plate, at the leading and trailing edges, respectively; Eq. (6) is similar to the one found in Couette flow.

The system of equations in the entire domain is solved by the central-difference equations, second-order in space, and by the modified Euler method for time integration. Further details of the numerical model and solution can be found in Hayatdavoodi and Ertekin (2014b,c) and Hayatdavoodi (2013). The forces and moment are then calculated by integrating the pressure around the plate at each time step. Note that the two-dimensional horizontal force is the force per unit thickness of the model.

\subsection{The long-wave approximation}

Propagation of long waves over a flat plate by assuming an inviscid and incompressible fluid and irrotational flow is studied by Siew and Hurley (1977). The solution was obtained by utilizing the linear potential theory subjected to appropriate (linear) boundary conditions. Wave length and plate width are assumed to be large compared with the water depth. Once the Laplace equation is solved, the velocity potential is found everywhere in the domain, and then the pressure distribution around the plate is calculated from Euler's integral. The final 
form of the wave loads on the submerged plate is given by Patarapanich (1984a) as

$$
\begin{aligned}
F_{x_{1}}= & -i \exp (-i k l) \exp (-i \omega t) 2 P, \\
F_{x_{3}}=- & i \exp (-i k l)\left(\frac{\sin k^{\prime} l-k^{\prime} l \cos k^{\prime} l}{k^{\prime} l \cos k^{\prime} l}\right) \\
& \quad \times \exp (-i \omega t) Q, \\
M_{x_{2}}=- & i \exp (-i k l)\left(\frac{\sin k^{\prime} l\left(3-\left(k^{\prime} l\right)^{2}\right)-3 k^{\prime} l \cos k^{\prime} l}{6\left(k^{\prime} l\right)^{2} \sin k^{\prime} l}\right) \\
& \times \exp (-i \omega t) P,
\end{aligned}
$$

where $F_{x_{1}}$ and $F_{x_{3}}$ are the two-dimensional horizontal and vertical forces, respectively, and $M_{x_{2}}$ is the overturning moment. $k$ and $k^{\prime}$ are the wave numbers in the upwave and above the plate regions, respectively, $l=B / 2, \omega$ is the incident (angular) wave frequency, and $P$ and $Q$ are complex constants given in Patarapanich (1984a).

\subsection{Euler's equations (OpenFOAM)}

Euler's equations along with the VOF interface tracking method are used to calculate the solitary wave forces on a flat plate and a deck with girders by Seiffert et al. (2014) and Hayatdavoodi et al. (2014), respectively. Here, we shall use the same model to calculate the cnoidal wave forces on a flat plate. The calculations are performed by use of the interFoam solver of OpenFOAM, an open source computational fluid dynamics software. In these calculations, the fluid is assumed to be incompressible and inviscid, and its motion is governed by Euler's equations:

$\nabla \cdot \boldsymbol{U}=0$

$\frac{\partial(\rho \boldsymbol{U})}{\partial t}+\nabla \cdot(\rho \boldsymbol{U} \boldsymbol{U})=-\nabla p_{\mathrm{d}}-\boldsymbol{g} \cdot \boldsymbol{x} \nabla \rho^{*}$,

where $\boldsymbol{U}$ is the velocity vector, $\boldsymbol{g}$ is the gravitational acceleration vector, $\boldsymbol{x}=\left(x_{1}, x_{2}, x_{3}\right)$ is the position vector, $p_{\mathrm{d}}$ is the dynamic pressure and $\rho^{*}$ is the density of the fluid, which may vary throughout the domain as there are multiple phases of air and water. To track the free surface of the cnoidal waves, a VOF interface capturing method is used. Details on the model and the numerical wave tank used for the calculations can be found in Seiffert et al. (2014). Cnoidal waves are generated by use of the waves2Foam package, which generates cnoidal waves based on the solution to the $\mathrm{KdV}$ equations, see Svendsen and Jonsson (1976). Further details on the numerical wavemaker waves2Foam can be found in Jacobsen et al. (2012).

\subsection{The empirical relations}

Two empirical relations, given by Douglass et al. (2006) and McPherson (2008) are used for comparison with the labora- tory measurements of vertical uplift force on an elevated plate in shallow-water. This is done because there is considerable interest in the engineering community to have rather simple equations that can be used to easily calculate the forces easily. The empirical (hydrostatic) relations suggested by Douglass et al. (2006) are similar to that given earlier by Wang (1970), and later by Overbeek and Klabbers (2001) and McConnell et al. (2004), and they depend on the difference of $\eta_{\max }$ (where $\eta_{\max }$ is the maximum water surface elevation) and elevation height $z^{*}$ (or deck clearance). The empirical relation of Douglass et al. (2006) for the vertical uplift and horizontal positive forces reads as

$F_{x_{3}}=C_{3}\left(\rho g\left(\eta_{\max }-z^{*}\right) A_{3}\right)$
$F_{x_{1}}=C_{1}\left(1+C_{\mathrm{r}}(N-1)\right)\left(\rho g\left(\eta_{\max }-\left(z^{*}+\frac{t_{\mathrm{p}}}{2}\right)\right) A_{1}\right)$,

where $C_{1}$ and $C_{3}$ are the empirical coefficients (recommended value is 1.0; however, it is suggested by the developers that 2.0 be used for conservative calculations), $C_{\mathrm{r}}=0.4$ is a reduction coefficient, $N$ is the number of girders and $A_{1}$ and $A_{3}$ are the projection area of the deck onto the vertical and horizontal planes, respectively.

The empirical relations of Douglass et al. (2006) were modified by McPherson (2008) by adding the weight of the overtopping (green) water on top of the plate for the vertical force and by considering the difference between the leading edge and trailing edge hydrostatic forces for the horizontal forces. The final form of the vertical force is given as

$F_{x_{3}}=F_{\mathrm{H}}+F_{\mathrm{B}}+F_{\mathrm{A}}$,

where $F_{\mathrm{H}}, F_{\mathrm{B}}$ and $F_{\mathrm{A}}$ are the hydrostatic force, bridge buoyancy force and the air entrapment force (assumed zero here), respectively, and are calculated as

$$
\begin{aligned}
& F_{\mathrm{H}}=\gamma \delta_{z} A_{3}-F_{\mathrm{w}}, \\
& F_{\mathrm{w}}=0.5 \gamma \delta_{z} A_{3}, \\
& F_{\mathrm{B}}=\gamma \operatorname{Vol}_{B},
\end{aligned}
$$

where $\gamma$ is the specific weight of water, $\delta_{z}=\eta_{\max }-\left(z^{*}+t_{\mathrm{p}}\right)$ is the elevation of the wave crest from the plate top, and $\mathrm{Vol}_{\mathrm{B}}$ is the volume of the plate. The equations for the horizontal force are given by Eqs. (6-8)-(6-12) of McPherson (2008). Note that $\delta_{z}$ may be negative if the maximum value of the surface elevation is below the top of the deck.

In this study, we refer to the relations given by Douglass et al. (2006) [Eqs. (10)-(11)] and McPherson (2008) [Eqs. (12)-(15)] simply as Douglass and McPherson relations, respectively. 
Fig. 5 The horizontal two-dimensional plate, used in the experiments and calculations, may be a elevated above the SWL, b located on the SWL, or $\mathbf{c}$ fully submerged. The figure shows the correct scale for water depth $h=0.071 \mathrm{~m}$ case

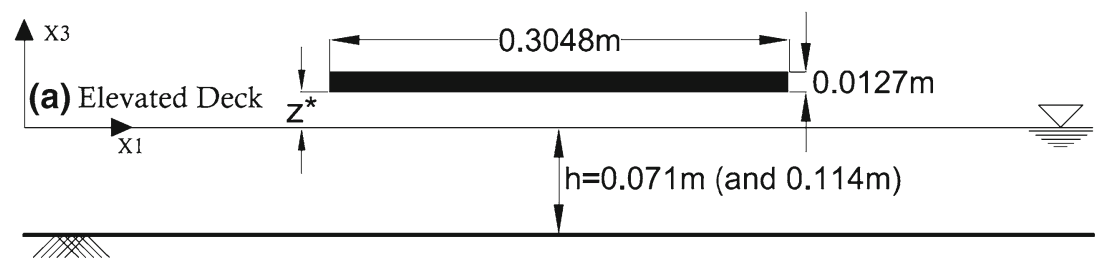

(b) Deck on the surface $\quad \mathrm{z}=0$

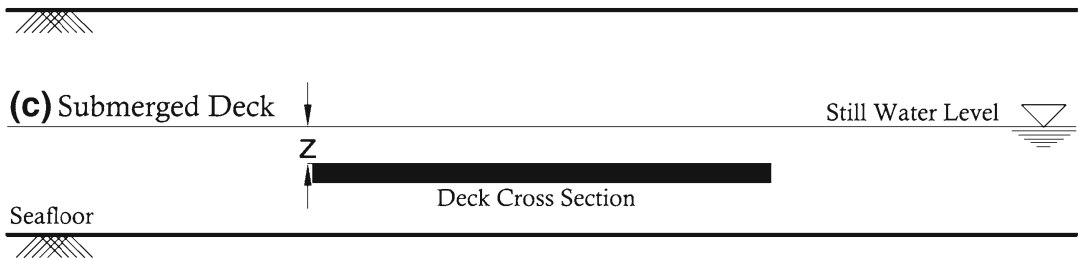

\section{Results and discussion}

Vertical and horizontal forces on a horizontally fixed flat plate under cnoidal wave loading measured during laboratory experiments and calculated numerically are given in this section. A comparison with previous laboratory measurements and theoretical estimations is also presented. Based on the location of the deck relative to the SWL, three cases are considered, including a fully elevated plate, a plate on the surface and a fully submerged plate, shown in Fig. 5. We shall present the results based on this relative location of the deck. We recall that a combination of two water depths $(h=0.071$ and $0.114 \mathrm{~m})$, five wavelengths $(\lambda=1.4,1.7,1.9,2.1,2.3 \mathrm{~m})$ and four wave heights $(H / h \approx 0.1,0.2,0.3$ and 0.4 ; the exact value of the wave heights are given in Tables 2,3) are considered. For the purpose of comparison with calculations, we only present theoretical results for two of the wavelengths, $\lambda=1.4$ and $2.3 \mathrm{~m}$.

Throughout this paper, the two-dimensional horizontal $\left(F_{x_{1}}\right)$ and vertical $\left(F_{x_{3}}\right)$ forces are presented in dimensionless forms as

$\bar{F}_{x_{1}}=\frac{F_{x_{1}}}{\rho g h t_{\mathrm{p}} L_{\mathrm{p}}}, \quad \bar{F}_{x_{3}}=\frac{F_{x_{3}}}{\rho g h^{2} L_{\mathrm{p}}}$.

Therefore, the two-dimensional horizontal force is the force per unit length and thickness of the plate, and the twodimensional vertical force is the force per unit length of the plate. Such nondimensionalization enables us to perform a direct comparison between the laboratory measurements and results of the theoretical models in which the plate is assumed to be thin (the GN and the LWA models). The dimensionless horizontal force (as presented here), therefore, is basically the average pressure on the projected surface (or curve, in two dimensions) of the model. Note also that the GN and LWA solutions are only applicable in the submerged plate case, shown in Fig. 5c.
Comparisons are provided in the form of time series and the maximum and minimum values of the forces. The uplift and downward forces are used to refer to the maximum and minimum values of the vertical force, respectively. Similarly, the maximum and minimum horizontal forces are referred to as horizontal positive and horizontal negative forces, respectively. These are also shown in Fig. 6. Next, we shall discuss the grid structure and convergence of the OpenFOAM calculations, followed by the results of the measurements and calculations of the wave forces on the flat plate.

\subsection{OpenFOAM grid construction and convergence}

In the OpenFOAM calculations, the two-dimensional physical domain is discretized by use of an unstructured mesh, finer around the body and free surface. A 1:1 scale of the flat plate used in the laboratory experiments is recreated.

Keeping the tank and plate dimensions fixed, three different mesh configurations are considered to assess the grid independency and convergence study. In all three mesh configurations, ratios of the change in grid sizes in all directions of the unstructured meshes are kept constant. Cell size on the model is kept the same in all configurations. Also, the maximum Courant number $\left(C r_{\max }=0.2\right)$ is kept constant throughout the calculations. Table 4 provides cell information of these three mesh configurations. The horizontal and vertical forces on a submerged and an elevated flat plate are calculated using each of these mesh configurations. The wave forces on the submerged plate are shown in Fig. 6. A similar study is performed on an elevated plate (fully above the SWL). We chose mesh ID III configuration for the calculations presented here.

In the calculations discussed in the following sections, the length of the numerical wave tank is kept fixed at $3.5 \lambda+B$. The upwave region has a length of $2 \lambda$, and downwave region is $1.5 \lambda$ long. A wave generation zone of $\lambda$ long is used at the 
Fig. 6 The two-dimensional vertical and horizontal forces on the submerged plate

$(h=0.071 \mathrm{~m}, z / h=0.6$, $\lambda=1.9 \mathrm{~m}, H / h \approx 0.3)$ using three mesh configurations. Mesh details are given in Table 4. Also shown are the vertical uplift and vertical downward forces and the horizontal positive and horizontal negative forces, used in the next sections for comparison purpose
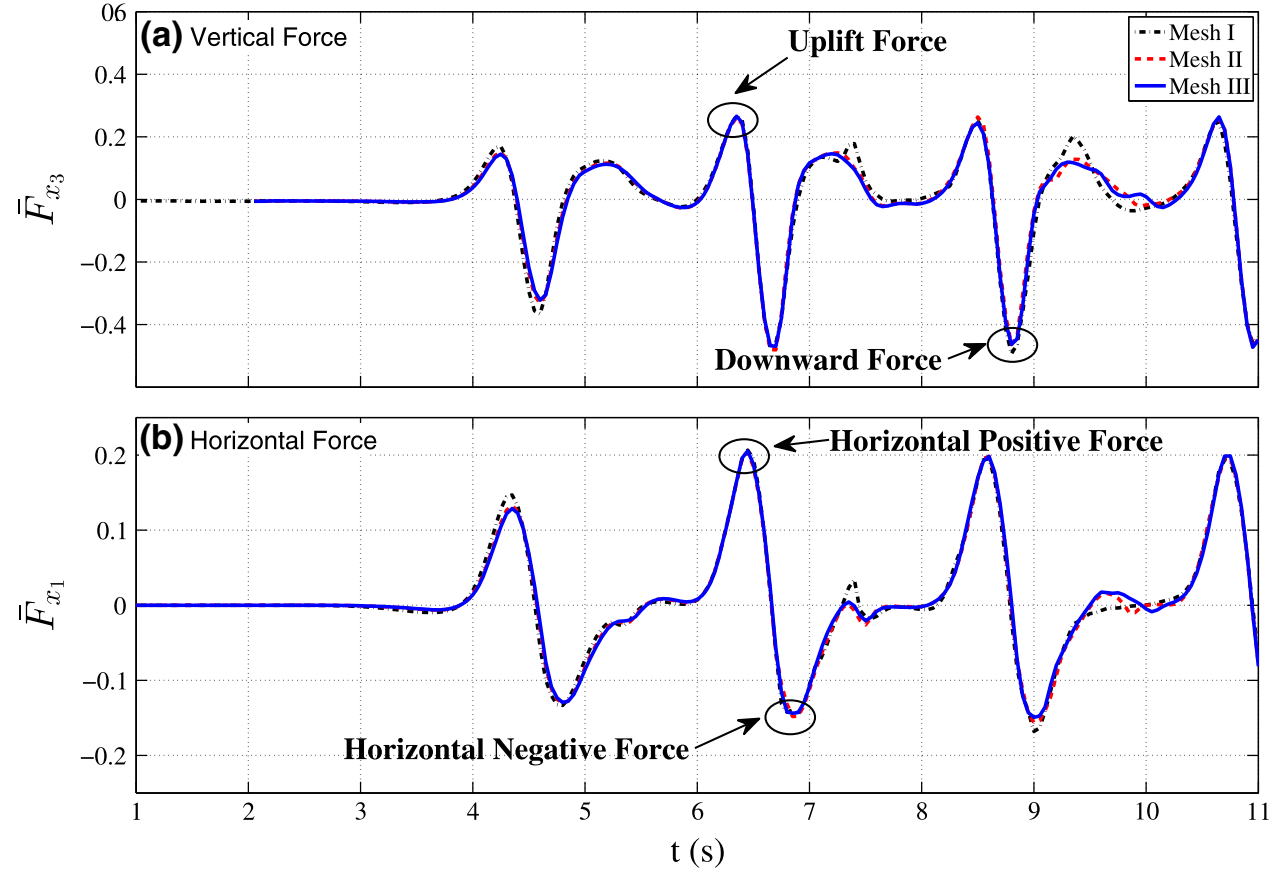

Table 4 Mesh configurations used in the grid study

\begin{tabular}{llll}
\hline Mesh ID & I & II & III \\
\hline$\Delta x_{1}$ on the plate (m) & 0.001 & 0.001 & 0.001 \\
$\Delta x_{3}$ on the plate (m) & 0.001 & 0.001 & 0.001 \\
Total cells, $x_{1}$ direction & 2,522 & 3,630 & 6,955 \\
Total cells, $x_{3}$ direction & 122 & 122 & 122 \\
Total number of cells & 303,719 & 438,895 & 844,545 \\
CPU time (h) & 5 & 8 & 32 \\
\hline
\end{tabular}

Seven Intel Core i7-4770 processor (8 M Cache, $3.4 \mathrm{GHz}$ ) CPUs (parallel computing method) are used utilizing a scotch parallel computing method. See C.F.D. (2012) for further details on parallel computing. The CPU time refers to the calculations of the case $h=0.071 \mathrm{~m}, z / h=0.6$, $\lambda=1.9 \mathrm{~m}, H / h \approx 0.3$

wavemaker side of the numerical tank, and a wave absorber zone of length $\lambda / 2$ is set on the opposite side of the twodimensional tank. The height of the tank is adjusted to the model elevation of the test cases and the wave height. The cell size, however, is fixed in all cases. Simulations are performed for 5.5T duration, where $T$ is the wave period. All the calculations in this paper are performed by use of OpenFOAM v. 2.1.1. Further information about the numerical details can be found in Seiffert et al. (2014) and Hayatdavoodi et al. (2014).

\subsection{Elevated deck}

In this subsection, we consider a flat plate that is located fully above the SWL (Fig. 5a). We shall first provide a comparison of the vertical wave force on an elevated flat plate, calculated by Euler's equations and the laboratory measure- ments of Bhat (1994). The intermediate-water condition considered in Bhat (1994) differs from the shallow-water conditions studied here. However, it provides an insight into the agreement of the results in the current study with those given in the literature.

In the experiments of Bhat (1994) and Isaacson and Bhat (1996), a thin flat plate $\left(B=60 \mathrm{~cm}, L_{\mathrm{p}}=20 \mathrm{~cm}\right.$ and $\left.t_{\mathrm{p}}=0.625 \mathrm{~cm}\right)$ is located at different elevations from the SWL and the vertical force of a series of periodic waves of different heights and periods are considered. Only the vertical force is measured in those experiments. We chose the case with the longest wave period and the largest wave height for the purpose of this comparison $(T=2.02 \mathrm{~s}, H=17.5 \mathrm{~cm}$ and $h=55 \mathrm{~cm})$. In the experiments of Bhat (1994), the vertical force on the plate is recorded by use of two supports and load-cells located in the middle and close to the trailing edge of the plate. Results are presented as the force recorded by each of the load cells, as well as a linear sum of these forces, referred to as the total vertical force. In such a setup, at the moment of the maximum vertical force, and at the load cell in the center of the plate, the second load cell records a negative force due to the negative moment exerted on the trailing side of the plate. The sum of the forces recorded by the load cells is, therefore, smaller than that recorded by the load cell in the center of the plate. This is slightly different with the setup in our calculations, in which the plate is fixed at all times and the force is a result of the integrated pressure. Here, we use the force recorded by the center load cell for the comparison (Fig. 4.8(b) of Bhat 1994).

The comparison of calculations based on Euler's equations and laboratory measurements of Bhat (1994) is shown 
in Fig. 7, for a plate located at $z^{*} / h=0.045$ (the highest elevation considered in the experiments of Bhat 1994). Good agreement is observed overall. A relatively smaller downward force is recorded in the experiments of Bhat (1994) when compared with the current calculations. This is likely due to the presence of the second support (and wave load) at the trailing side of the plate in the laboratory experiments.

Next, we return to the problem of interaction of cnoidal waves with an elevated plate considered in the current study. Figure 8 shows a comparison of the surface elevation recorded at three wave gauges upwave and downwave from the plate, and the vertical and horizontal forces measured in the laboratory experiments and as calculated here by Euler's equations. Wave breaking occurs as the crest of the wave impinges on the leading side of the plate, resulting in significant reflection, and reduction in wave height of the transmitted wave. A very close agreement of the surface elevation at all three wave gauges is observed, both for the main wave and the reflected and transmitted waves.
Fig. 7 Comparison of the two-dimensional vertical force on a plate located above the SWL, measured by Bhat (1994) vs. calculations based on Euler's equations. $h=55 \mathrm{~cm}$, $T=2.02 \mathrm{~s}, H=17.5 \mathrm{~cm}$, $B=60 \mathrm{~cm}, L_{\mathrm{p}}=20 \mathrm{~cm}$ and $t_{\mathrm{p}}=0.625 \mathrm{~cm}$

Fig. 8 Comparison of surface elevation and dimensionless forces of the laboratory measurements and calculations of Euler's equations of interaction of cnoidal waves with a fully elevated plate, $h=0.071 \mathrm{~m}, H / h \approx 0.4$, $\lambda=1.9 \mathrm{~m}$ and $z^{*} / h=0.1$
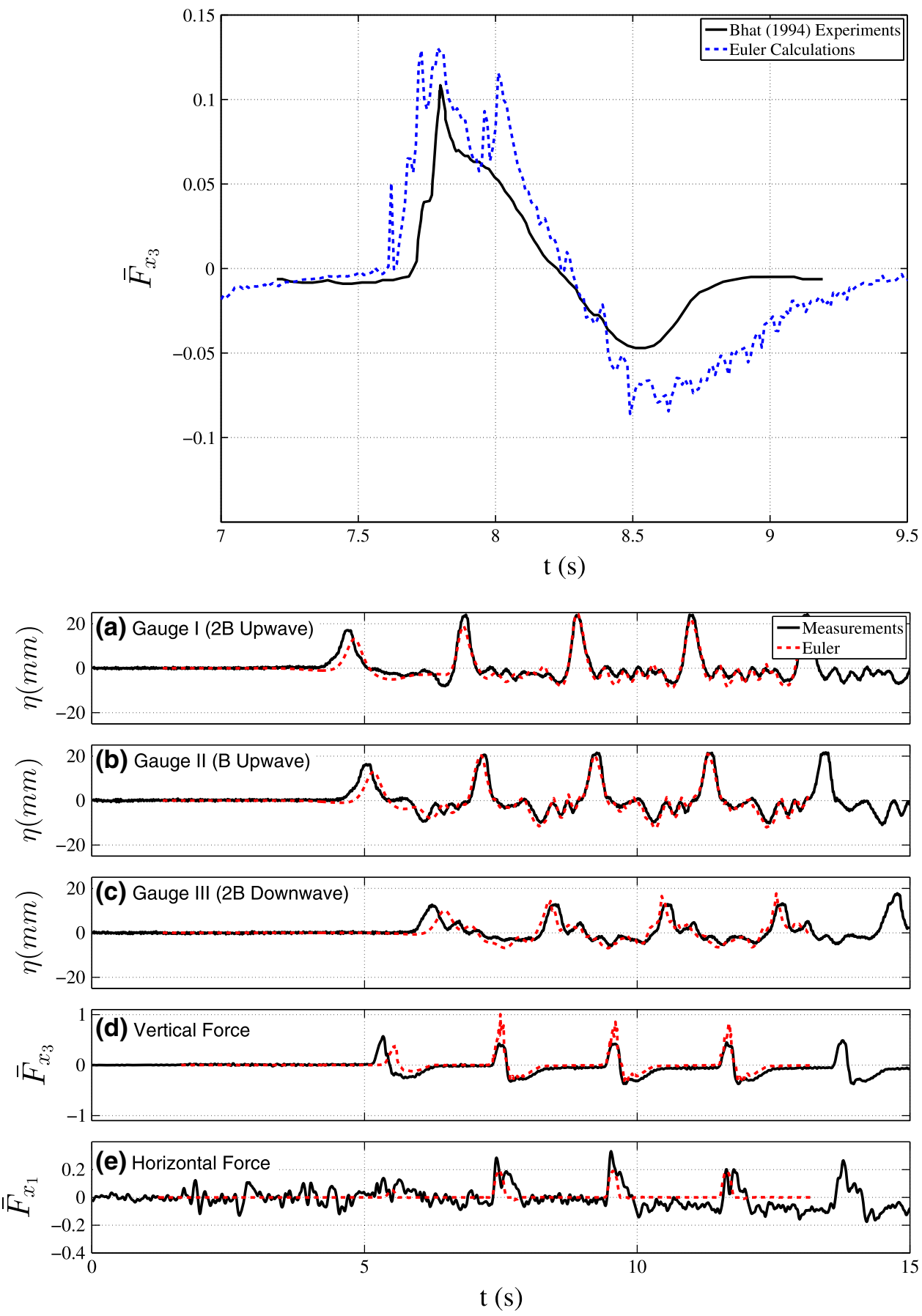
Fig. 9 a Vertical uplift and b vertical downward forces on an elevated plate due to cnoidal waves of different wavelengths and wave heights ( $h=0.071 \mathrm{~m}$, $\left.z^{*} / h=0.06\right)$, measured in the laboratory experiments and calculated by the empirical relations
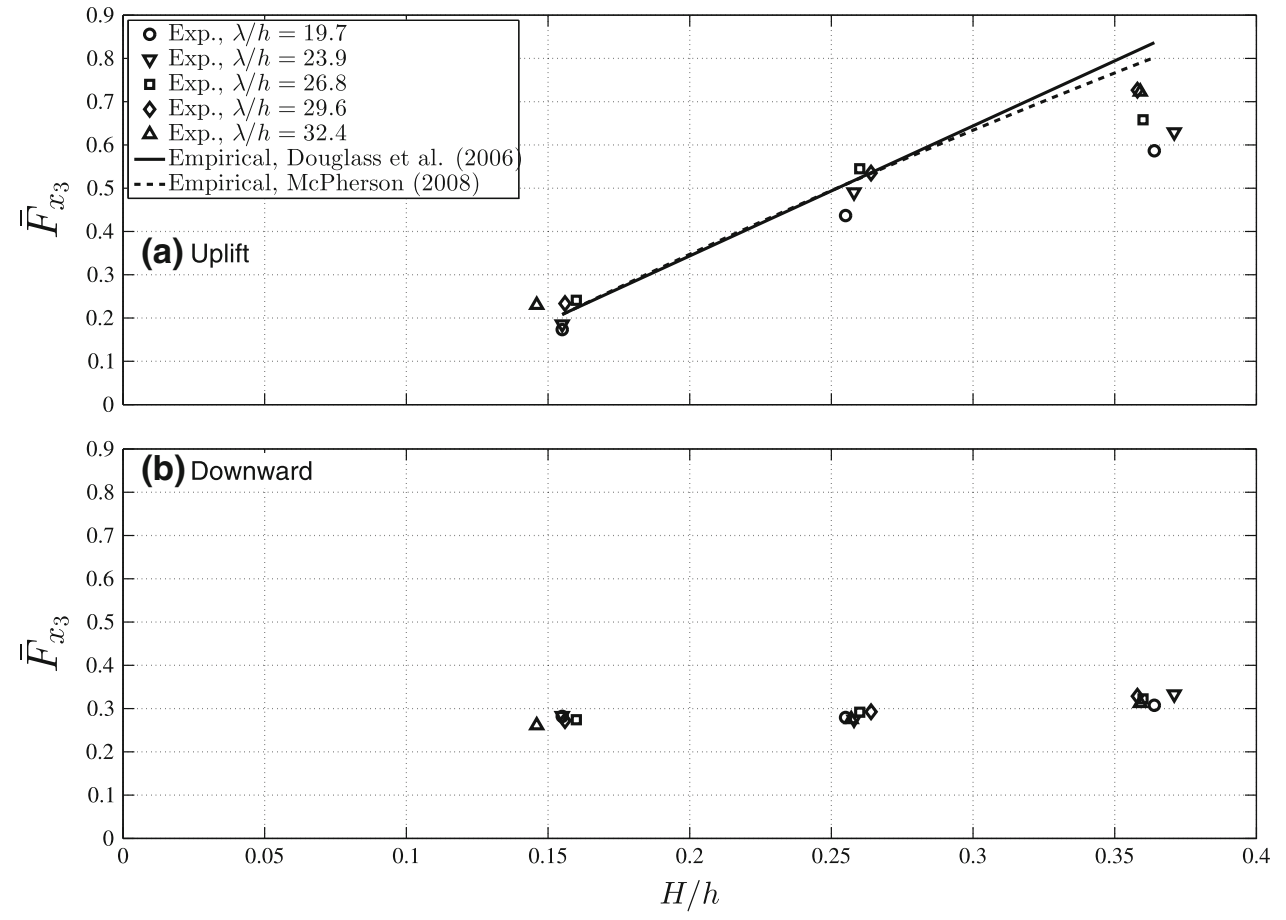

Fig. 10 a Vertical uplift and b vertical downward forces on an elevated plate due to cnoidal waves of different wavelengths and wave heights ( $h=0.071 \mathrm{~m}$, $\left.z^{*} / h=0.1\right)$, measured in the laboratory experiments and calculated by the empirical relations. The Euler equations predict (a) 0.85 and (b) 0.3 for $H / h \approx 0.4$ and $\lambda / h=26.8$
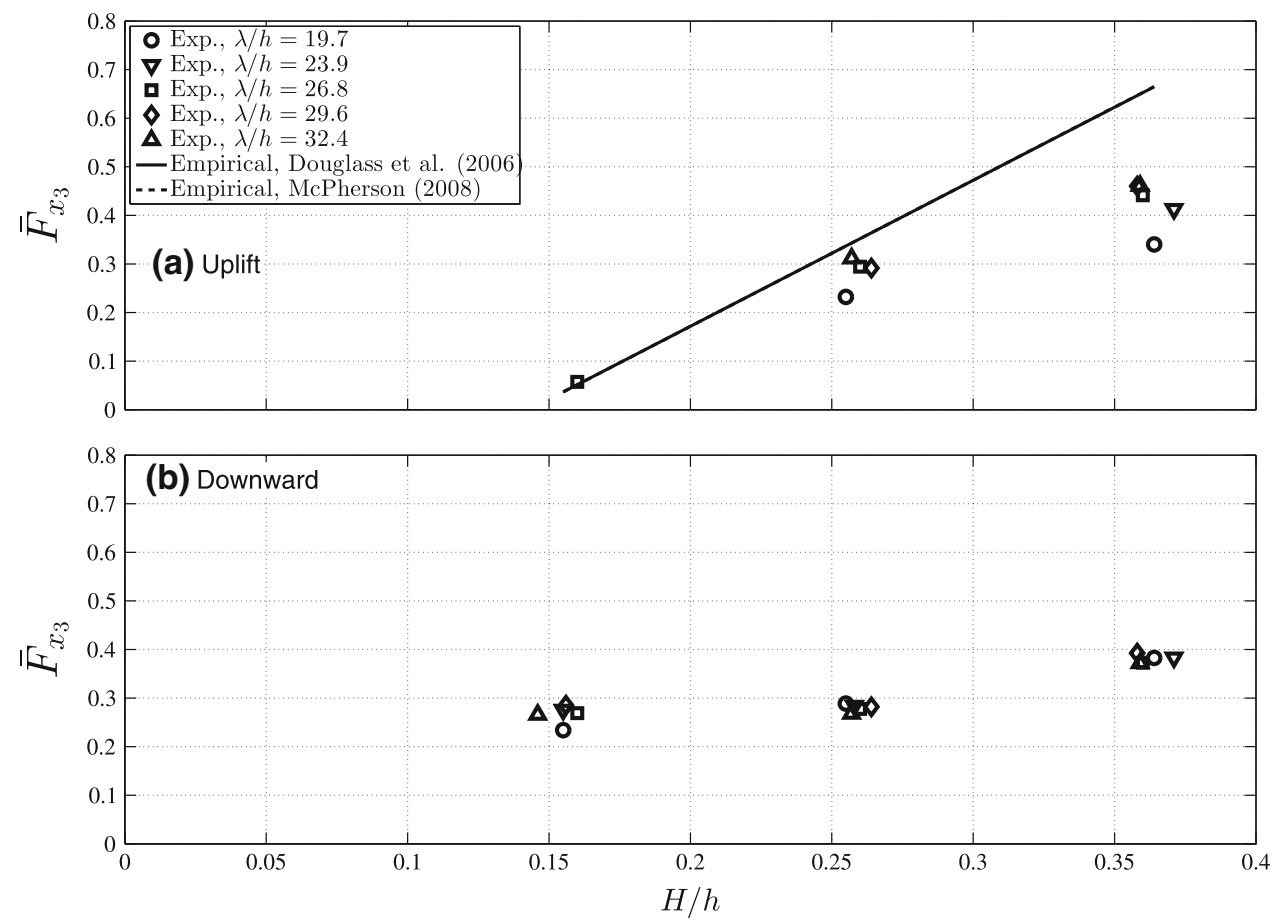

As the crest of the wave approaches the model, it exerts a relatively large uplift force on the plate. This occurs in the first moments of fluid-structure interaction. Shown in Fig. 8d, the uplift force is followed by a very small downward force, mainly due to the weight of water on top of the plate and the final stage of the interaction. Figure 8e shows a relatively large positive horizontal force (in the direction of wave propagation) experienced by the plate at about the same time as when the wave touches the leading side of the plate. The vertical forces on the plate calculated by Euler's equations and measured in the laboratory experiments are in good agreement, while the peak of the horizontal force (horizontal positive force) is slightly smaller in the calculations.

Small variations in horizontal force seen in the beginning of the time series in Fig. 8e (before waves have hit the struc- 
Fig. 11 a Vertical uplift and b vertical downward forces on an elevated plate due to cnoidal waves of different wavelengths and wave heights ( $h=0.114 \mathrm{~m}$, $\left.z^{*} / h=0.06\right)$, measured in the laboratory experiments and calculated by the empirical relations

Fig. 12 a Vertical uplift and b vertical downward forces on an elevated plate due to cnoidal waves of different wavelengths and wave heights ( $h=0.114 \mathrm{~m}$, $\left.z^{*} / h=0.1\right)$, measured in the laboratory experiments and calculated by the empirical relations
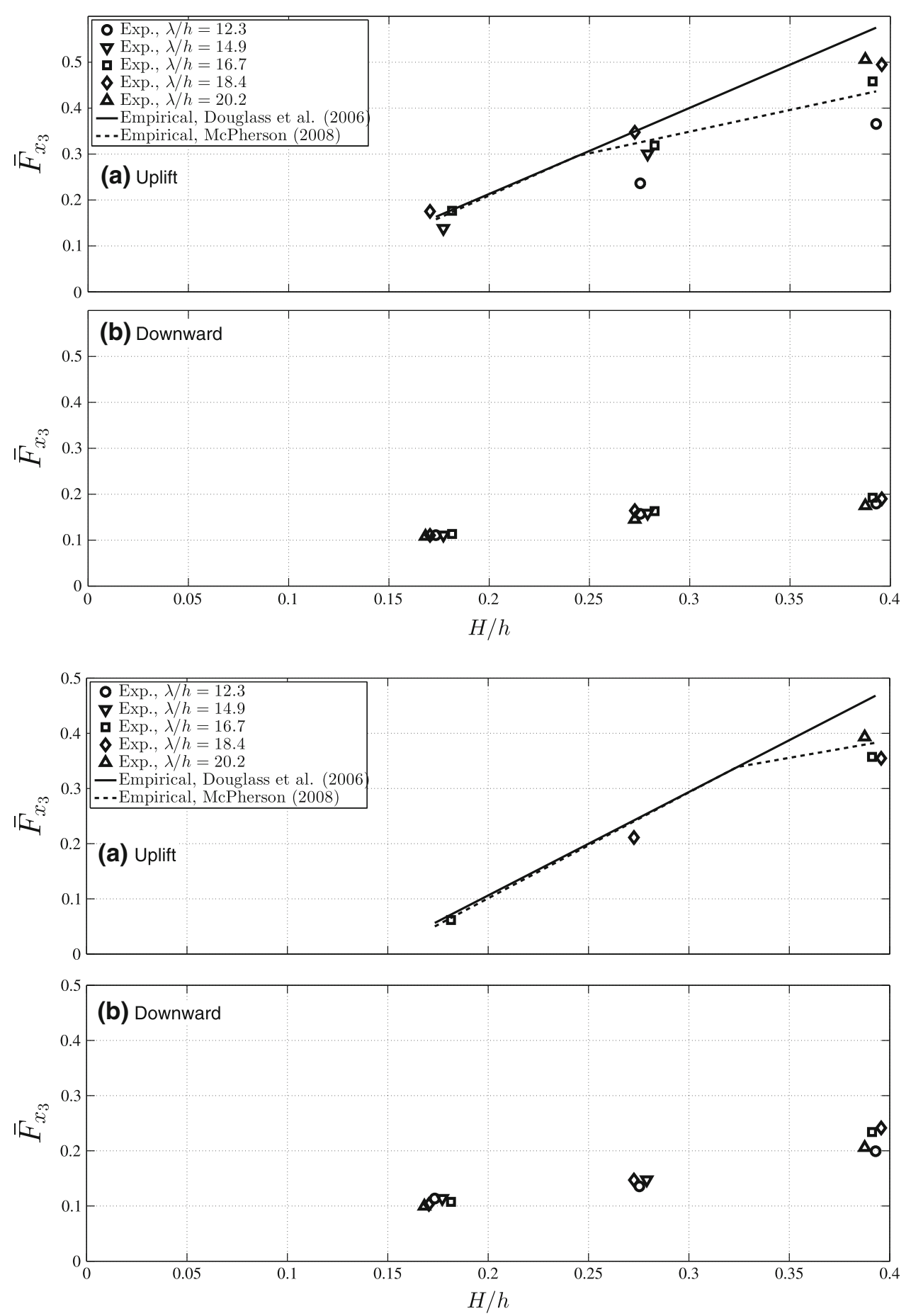

ture) are attributed to small vibrations along the flume walls due to the movement of the wavemaker.

A comparison of the vertical uplift and vertical downward forces on the elevated plate, measured in the laboratory experiments and calculated using the existing empirical relations of Douglass et al. (2006) and McPherson (2008), is given in Figs. 9 and 10 for $h=0.071 \mathrm{~m}$, and in Figs. 11 and 12 for $h=0.114 \mathrm{~m}$ case. The empirical relations only provide the vertical uplift and horizontal positive forces. For the calcula- tions of the empirical forces here, the maximum surface elevation from the SWL is approximated by $\eta_{\max }=0.7 \mathrm{H}$. We note that in calculating the force using McPherson's method, the weight of the green-water on top of the deck is set to zero when $\eta_{\max }<z^{*}+t_{\mathrm{P}}$, i.e., when surface elevation is smaller than the top surface of the deck and water does not go over the deck. Therefore, McPherson's results are piecewise linear in wave height. Note that for these cases, $\delta_{z}=\eta_{\max }-\left(z^{*}+t_{\mathrm{P}}\right)$, which is a negative value, is used to calculate $F_{\mathrm{H}}$ in Eq. (13). 
Fig. 13 Comparison of surface elevation and dimensionless forces of the laboratory measurements and calculations interaction of cnoidal waves with a plate located on the SWL ( $h=0.071 \mathrm{~m}, H / h \approx 0.4$, $\lambda=1.9 \mathrm{~m}$ and $z / h=0.0)$ of Euler's equations of
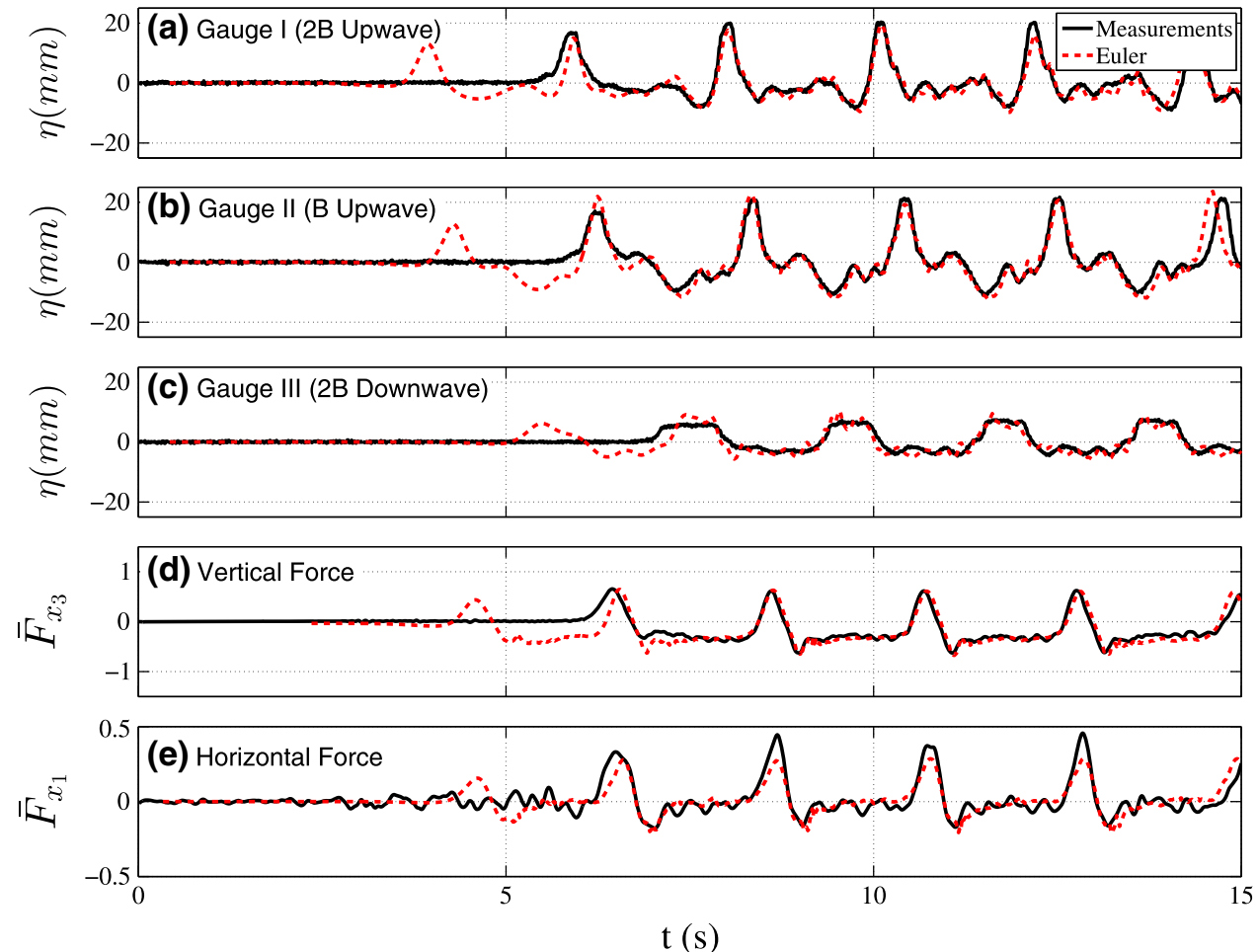

$\mathrm{t}(\mathrm{s})$
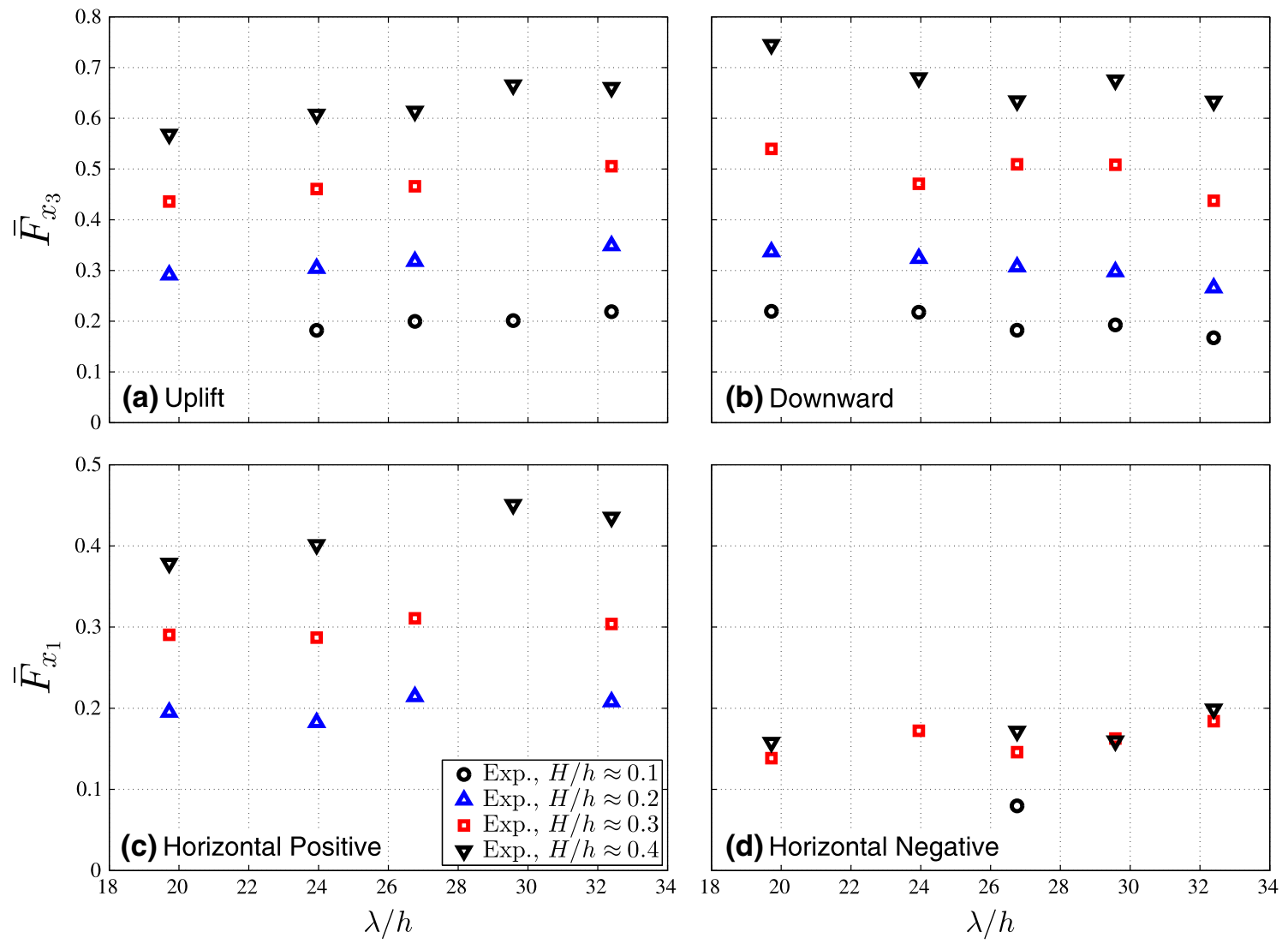

Fig. 14 Laboratory measurements of a vertical uplift, b vertical downward, $\mathbf{c}$ horizontal positive and $\mathbf{d}$ horizontal negative forces of cnoidal waves of different wave height and wavelengths impinging on a plate located on the SWL ( $h=0.071 \mathrm{~m}$, and $z / h=0.0$ ). The Euler equations predict a $0.63, \mathbf{b} 0.65$, c 0.28 and $\mathbf{d} 0.2$ for $H / h \approx 0.4$ and $\lambda / h=26.8$ 

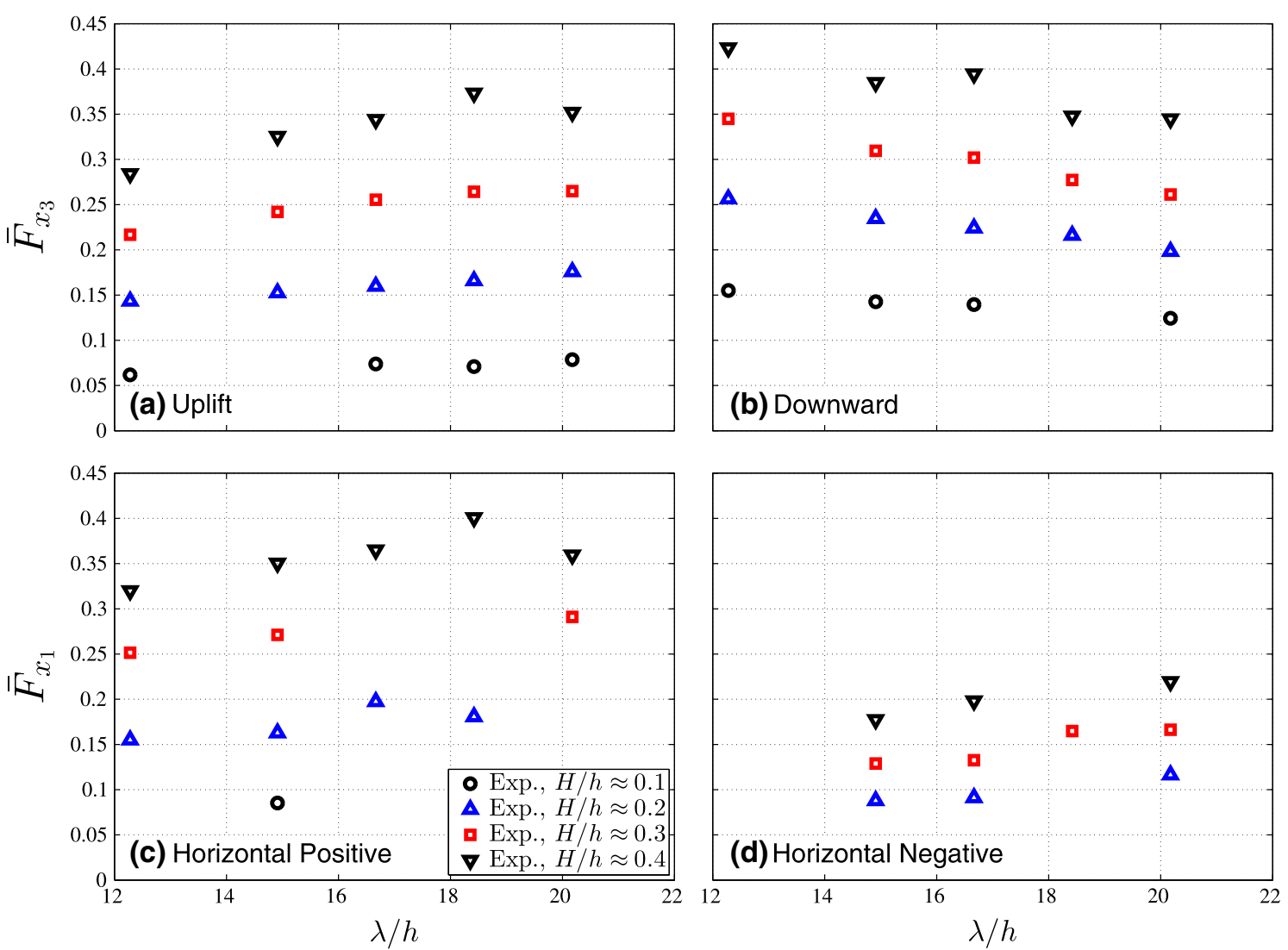

Fig. 15 Laboratory measurements of a vertical uplift, $\mathbf{b}$ vertical downward, $\mathbf{c}$ horizontal positive and $\mathbf{d}$ horizontal negative forces of cnoidal waves of different wave height and wavelengths impinging on a plate located on the SWL $(h=0.114 \mathrm{~m}$, and $z / h=0.0)$

Fig. 16 Comparison of surface elevation and dimensionless forces of the laboratory measurements and calculations of Euler's equations and the GN equations of interaction of cnoidal waves with a submerged plate $(h=0.071 \mathrm{~m}, H / h \approx 0.3$, $\lambda=1.9 \mathrm{~m}$ and $z / h=0.6)$
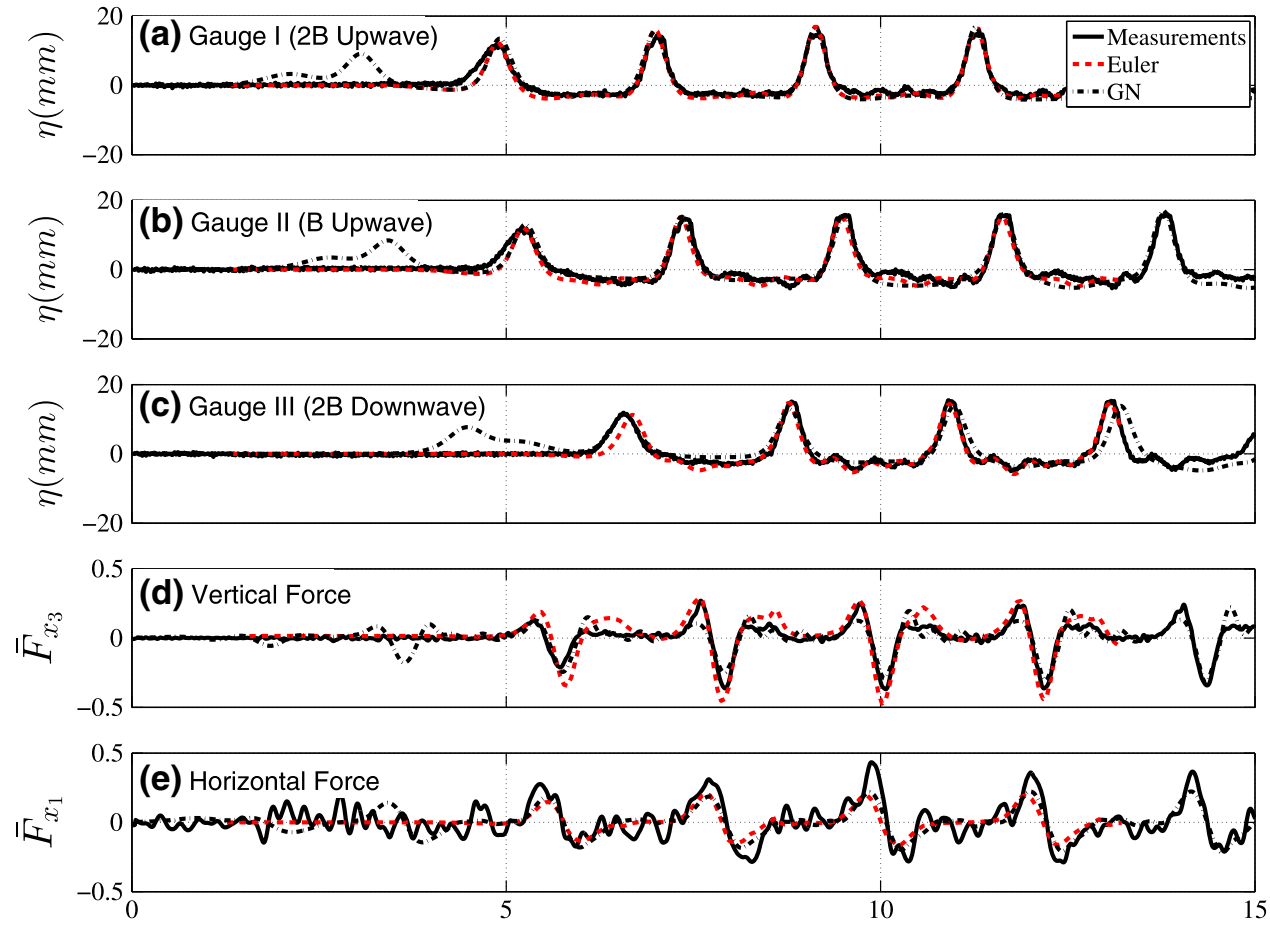

$\mathrm{t}(\mathrm{s})$ 
Also, per McPherson (2008) the entire volume of the deck is considered in calculating the buoyancy force of the model, which contributes to the uplift force. Obviously, this is a conservative assumption, as in most cases studied here, at the moment of the maximum uplift force, only a portion of the deck is covered by the wave crest.

Results are presented for a combination of five wavelengths and two elevations $\left(z^{*} / h=0.06\right.$ and 0.1$)$. The empirical relations do not include any wave periodicity parameter (wave period or wavelength), and thus one value is shown for all wavelengths. Only the vertical forces are considered here, as the horizontal forces showed a large repeatability error in the laboratory experiments. Figures 9, 10, 11 and 12 show slightly larger uplift force measured for longer wavelengths and very little variation in downward force measured for different wavelengths.

We note that AASHTO's empirical relations (2008) for the vertical and horizontal forces of cnoidal waves considered here overestimate the force by 10-100 times. This is expected, as the empirical equations and the series of coefficients in the equations are not applicable to such nonlinear shallow-water waves; AASHTO's relation for the wave forces are applicable to the limit of $0.035 \leq H / \lambda \leq 0.15$ and $3 \mathrm{~s} \leq T \leq 10 \mathrm{~s}$, see section 6.1.2 of AASHTO (2008), a range that does not include any of the waves studied here, i.e., nonlinear shallow-water waves.

Overall, Douglass and McPherson's relations are in some agreement with the results of the laboratory experiments. The empirical relations have overestimated the uplift force almost in all cases. The agreement is better for $z^{*} / h=0.06$ when compared to $z^{*} / h=0.1$ for both water depths and also for smaller wave heights in all cases. We note that $C_{3}=$ 1 is used in Eq. (10) to calculate the vertical force by the Douglass relation. For conservative calculations, Douglass et al. (2006) suggested the use of $C_{3}=2$, i.e., results in Figs. 9, 10, 11 and 12 would become $100 \%$ larger. As the empirical relations do not consider the wave periodicity, we expect less agreement for $\lambda / B \approx 1$, when the wave loads undergo significant oscillation with wave period.

\subsection{Deck on the surface}

A plate with its top surface level with the SWL is considered in this subsection (Fig. 5b). Results for a combination of two water depths, five wavelengths and four wave heights are presented.

A comparison of the surface elevation and forces calculated by Euler's equations and measured in the laboratory experiments is shown in Fig. 13. The incident wave breaks in all cases as it propagates over the plate. The breaking point varies with wave height, but it is mostly on the leading edge of the plate. Due to wave breaking, only a small portion of the wave energy is transmitted, resulting in smaller waves
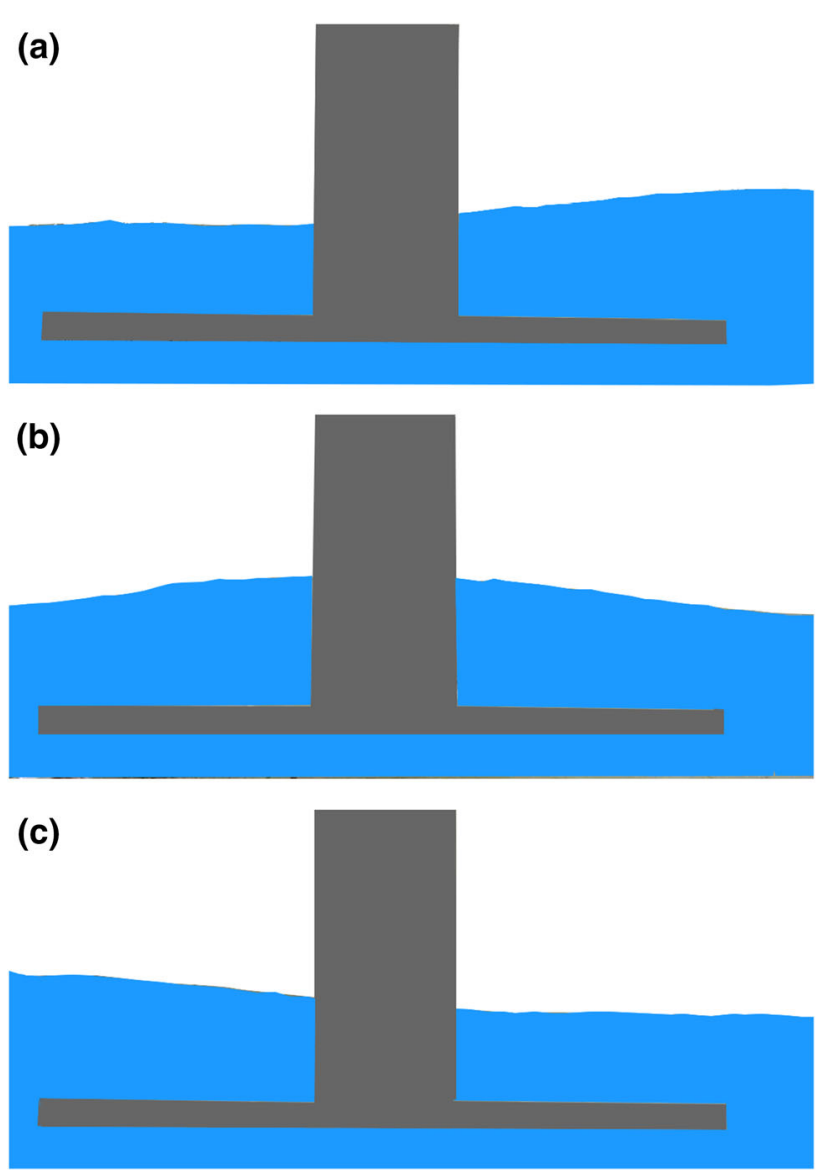

Fig. 17 Snapshots of the interaction of cnoidal waves (propagating from right to left) with a submerged plate $(h=0.071 \mathrm{~m}, H / h \approx 0.3$, $\lambda=1.9 \mathrm{~m}$ and $z / h=0.6$ ) of the laboratory experiments, showing a wave crest at the leading edge of the plate, $\mathbf{b}$ wave crest in the middle of the plate and, $\mathbf{c}$ wave crest at the trailing edge of the plate. These snapshots are digitally extracted from optical images of the laboratory experiments

downwave. A very close agreement is observed for the surface elevations at all wave gauges upwave and downwave; the main wave and the reflected and transmitted higher harmonics are in a good agreement. This reveals that the wave breaking process is modeled with good accuracy by Euler's equations in OpenFOAM. Note that the first incoming wave in the solution of Euler's equations, seen in Gauge I of Fig. 13 (at $t \approx 4 \mathrm{~s}$ ), is due to the use of a ramp function in generating cnoidal waves in OpenFOAM, see Hayatdavoodi (2013) for further details. The vertical force on the plate, Fig. 13d, has a relatively larger uplift component, which occurs as the crest of the wave approaches the leading edge of the wave, followed by a smaller downward force, as the crest of the main wave propagates over the plate and leaves the trailing edge of the plate. The calculations and the laboratory measurements show excellent agreement with both the uplift and downward components of the vertical force.

Shown in Fig. 13e is the horizontal force that has a relatively larger positive peak (horizontal positive force) as the 
wave impinges on the leading side of the plate, and this is followed by a smaller negative peak (horizontal negative force, opposite to the wave propagation direction) as the crest of the wave propagates over the trailing edge of the plate. The positive horizontal force is slightly larger as recorded in the laboratory experiments. The horizontal negative force of the computations and measurements are in very good agreement.

Results of the laboratory measurements of the cnoidal wave forces on a plate located on the SWL are shown in Figs. 14 and 15 , for $h=0.071$ and $0.114 \mathrm{~m}$ water depths, respectively. As with the case of the elevated plate, there are slightly larger uplift forces with longer wavelengths, but in this case, there are also slightly smaller downward forces with longer wavelengths. For longer waves, there is more time for the green water to drain off the top of the plate before the plate is hit by another wave. The smaller volume of the green water weighing down on the plate results in a larger uplift force and smaller downward force with longer wavelengths. Horizontal forces show little variability with change in wavelength.

It is interesting that the magnitude of the vertical downward force is comparable to (and sometimes larger than) the vertical uplift force, particularly for larger wave heights. This is mainly due to the weight of the wave crest (weight of the excess mass due to the presence of the wave crest on top of the plate) and wave breaking on top of the plate which results in a downward component on the top surface of the deck.

\subsection{Submerged deck}

Forces on a fully submerged deck in shallow-water due to the propagation of cnoidal waves are considered in this subsection, see Fig. 5c. A range of plate submergence depths are studied, including the cases of a submerged plate closer to the SWL $(z / h=0.2)$ to a deeply submerged plate $(z / h=0.6)$. Wave breaking is observed in some of the cases in which the plate is closer to the SWL and for large wave heights. For the non-breaking cases, $z / h \geq 0.4$, a linear solution known as the Long-Wave Approximation and a nonlinear solution based on the GN equations are compared with laboratory measurements.

Figure 16 shows a comparison of the time series from the calculations and laboratory measurements of the surface elevation, upwave and downwave from the model, and the cnoidal wave (vertical and horizontal) forces on the submerged plate. Both Euler's equations and the GN equations are considered in this comparison. A very good agreement
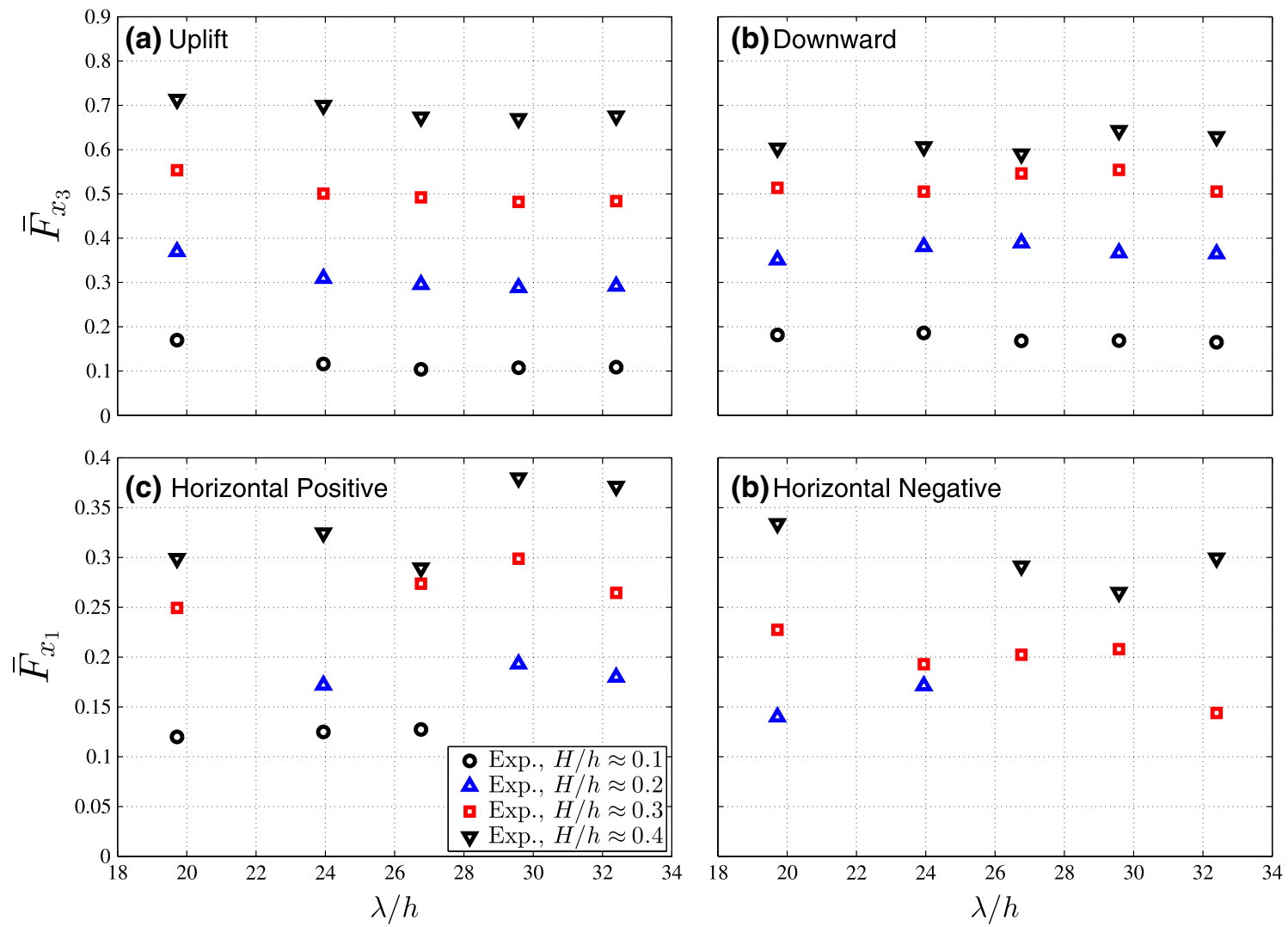

Fig. 18 Laboratory measurements of a vertical uplift, $\mathbf{b}$ vertical downward, $\mathbf{c}$ horizontal positive and $\mathbf{d}$ horizontal negative forces of cnoidal waves of different wave height and wavelengths propagating over a submerged plate $(h=0.071 \mathrm{~m}$ and $z / h=0.2)$ 
is seen in the surface elevation recorded upwave and downwave. Due to the presence of the submerged plate, part of the wave reflects back towards the wavemaker, but a significant portion of the energy is transmitted downwave, which varies with the submergence depth and the $\lambda / h$ ratio, see Patarapanich (1984b), Carter et al. (2006), Brossard et al. (2009) and Liu et al. (2009). Reflection and transmission of the waves are captured by Euler' equations and the GN equations and are in close agreement with the laboratory measurements.

In Fig. 17, snapshots of the laboratory experiments show the interaction of cnoidal waves with a submerged plate. As the wave initially interacts with the plate (Fig. 17a), there is an initial vertical uplift force followed by a positive horizontal force as the wave advances further towards the plate. The uplift force is explained by both the vertical particle accelerations under the crest as well as hydrostatic pressure due to the incoming wave. The horizontal force is due to both the horizontal particle accelerations as well as the difference in pressure at the leading and trailing edges of the plate when the crest is at the leading edge of the plate. As the wave travels over the plate (Fig. 17b), a downward force is measured on the plate, mainly due to the weight of the water under the wave crest. As the wave leaves the plate (Fig. 17c), a nega- tive horizontal force is measured on the plate, again due to both horizontal particle accelerations, this time acting in the opposite direction, and the pressure differential between the leading and trailing edges of the plate.

As the crest of the main wave approaches the leading edge of the plate, a vertical uplift force and a horizontal positive force (in the direction of wave propagation) are exerted on the submerged plate, see Fig. 16d, e. The calculated and measured vertical uplift forces are in excellent agreement. The horizontal positive force recorded in the laboratory is slightly larger than the calculations. As the wave propagates on the top of the plate, the vertical uplift force is followed by a vertical downward force, mainly due to the weight of the water under the wave crest. The magnitude of the downward force is larger than the uplift force in this case. This, however, changes with the submergence depth and wave conditions. Both calculations predict this component of the vertical force in close agreement with the laboratory data. Some small differences in the GN calculations are due to the assumption of the plate having zero thickness in the theory. It is important to emphasize that, in this case, the submergence depth is defined as the distance from the SWL to the middle surface of the deck (rather than the top or bottom surfaces). Notice that the plate thickness is $18 \%$ of water depth $\left(t_{\mathrm{p}} / h=0.18\right)$ in
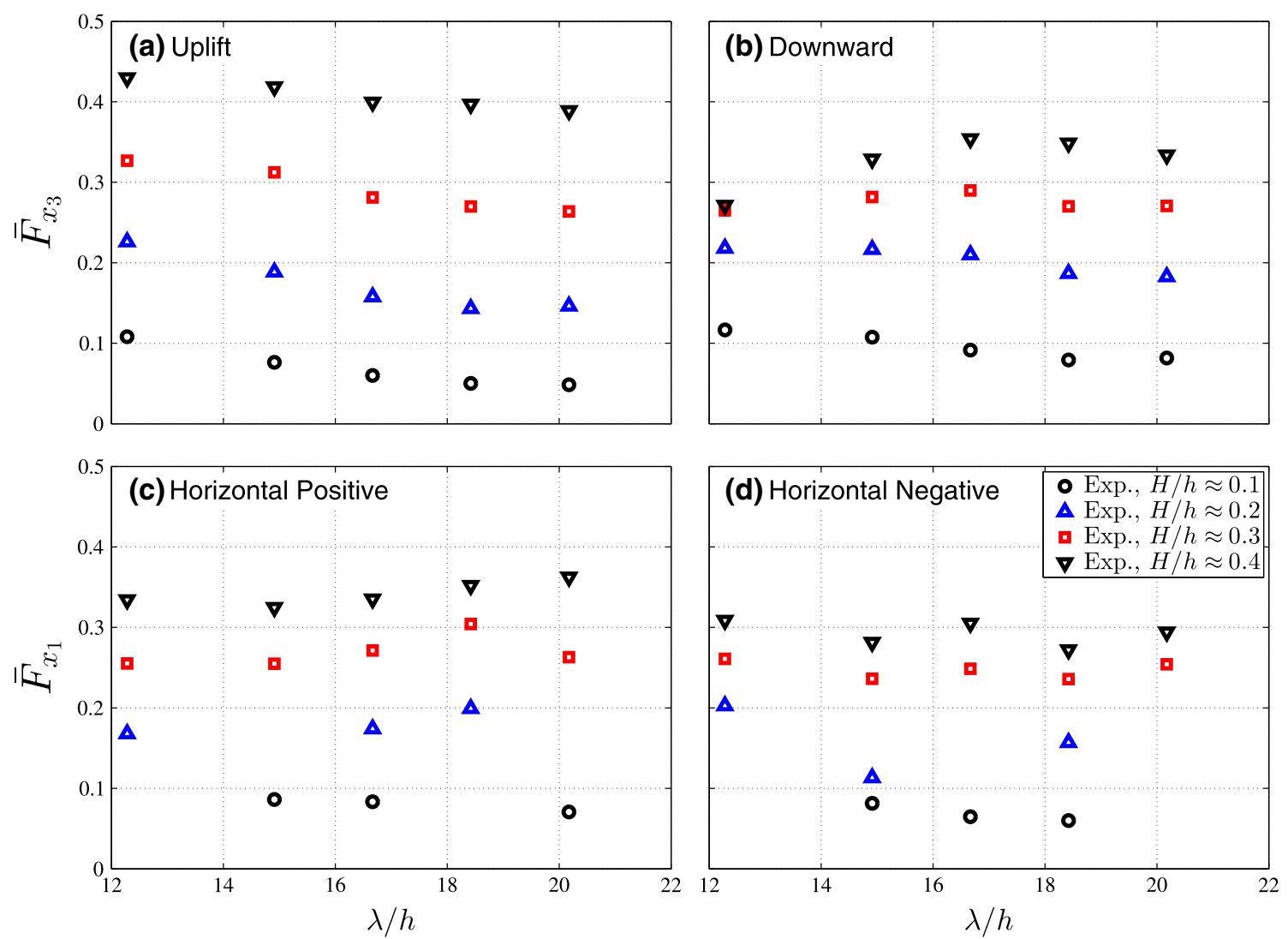

Fig. 19 Laboratory measurements of a vertical uplift, $\mathbf{b}$ vertical downward, $\mathbf{c}$ horizontal positive and $\mathbf{d}$ horizontal negative forces of cnoidal waves of different wave height and wavelengths propagating over a submerged plate $(h=0.114 \mathrm{~m}$ and $z / h=0.2)$ 
the case shown in Fig. 16. The slight difference of the water column above the plate in the GN calculations, compared to calculations based on Euler's equations and the laboratory measurements, directly results in some differences of the vertical downward force.

As the crest of the wave passes the trailing edge of the plate, a negative component of the horizontal force is experienced by the plate, see Fig. 16e. Computations of Euler's equations and the GN equations of the negative horizontal force show close agreement with the laboratory measurements. Note that the vertical force maxima and minima are slightly out of phase with the horizontal force maxima and minima.

Laboratory measurements of the cnoidal wave forces on a fully submerged plate $(z / h=0.2)$ are shown in Figs. 18 and 19 , for $h=0.071$ and $0.114 \mathrm{~m}$ water depths, respectively. A combination of five wavelengths and four wave heights are presented. At this submergence depth, wave breaking is observed for some of the cases of large wave heights. Wave breaking occurs at a later time compared with the case of the plate on the surface. The vertical uplift and vertical downward forces show very small variation with the wavelength. The horizontal forces, on the other hand, appear to show some oscillations with the wavelength, particularly in the $h=0.071 \mathrm{~m}$ water-depth case.
The magnitude of the vertical downward force, shown in Figs. 18 and 19a, b, is larger than the vertical uplift force for $H / h \leq 0.2$ at this submergence depth. This changes as the wave height increases, such that the vertical uplift force becomes larger for $H / h>0.3$. This is likely due to the wave breaking earlier with larger $H / h$ ratios, resulting in smaller downward force.

Comparisons of the cnoidal wave forces on a fully submerged plate, calculated by the GN and the LWA theories, and laboratory measurements, are shown in Figs. 20, 21, 22 and 23 , for a combination of two wavelengths $(\lambda=1.4$ and $1.9 \mathrm{~m}$ ), four wave heights, two submergence depths $(z / h=0.4$ and 0.6$)$ and two water depths $(h=0.071$ and $0.114 \mathrm{~m})$.

In almost all cases, the forces are underestimated by the LWA theory for $\lambda=1.9 \mathrm{~m}$. As the wavelength decreases to $\lambda=1.4 \mathrm{~m}$, and for smaller wave heights, the LWA results show closer agreement with the GN equations and the laboratory measurements. This is mainly due to the nonlinearity of the wave forces for longer wave lengths and larger wave heights.

The GN results are in good agreement with the laboratory measurements, particularly for the $h=0.114 \mathrm{~m}$ case, shown in Figs. 21 and 23. At this water depth, $t_{\mathrm{p}} / h=0.11$, a closer value to the assumption of thin plate in the GN equations.
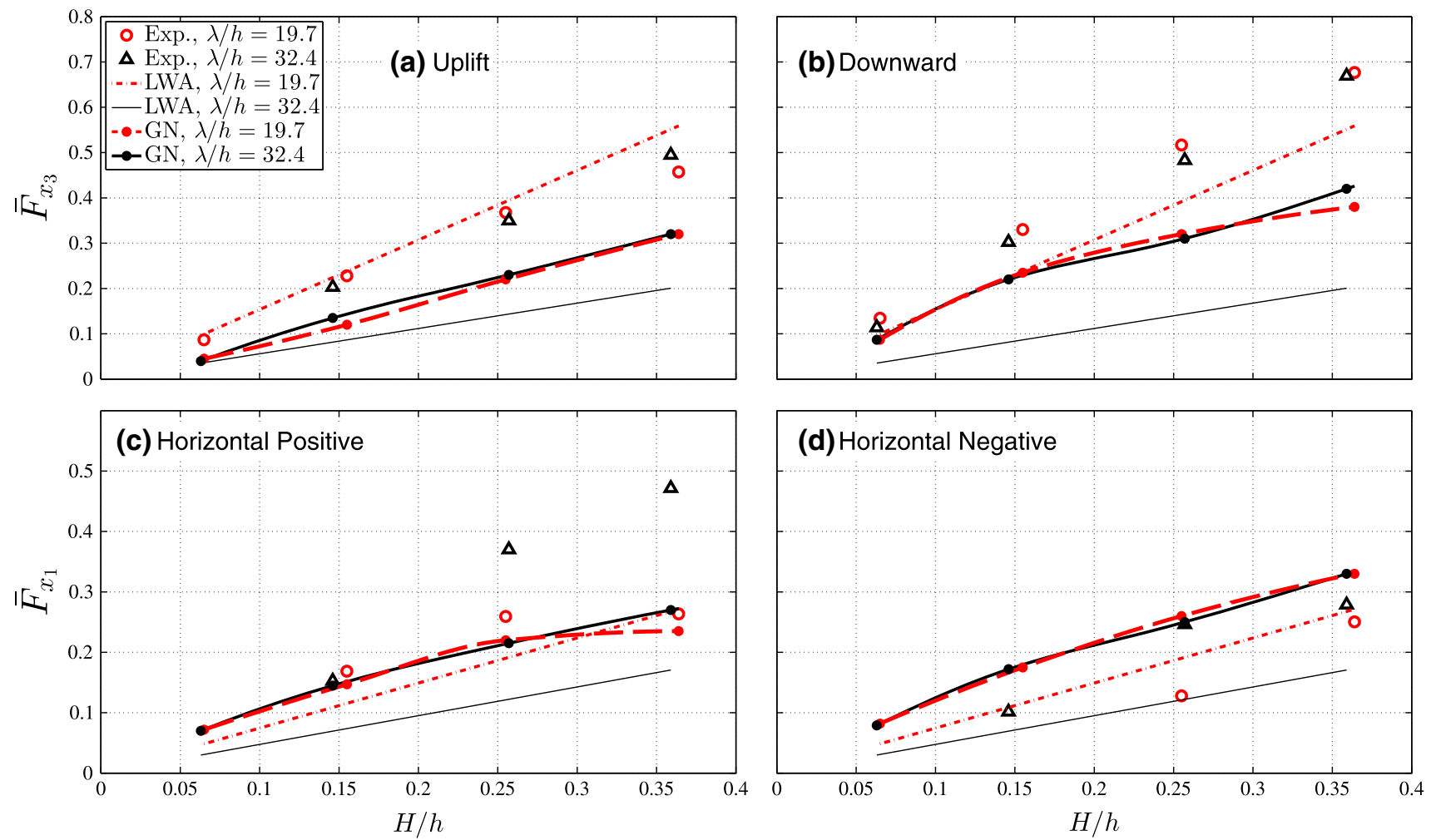

Fig. 20 Laboratory measurements and the GN and LWA calculations of a vertical uplift, b vertical downward, $\mathbf{c}$ horizontal positive and, $\mathbf{d}$ horizontal negative forces of cnoidal waves of different wave height and wavelengths propagating over a submerged plate $(h=0.071 \mathrm{~m}$ and $z / h=0.4)$ 

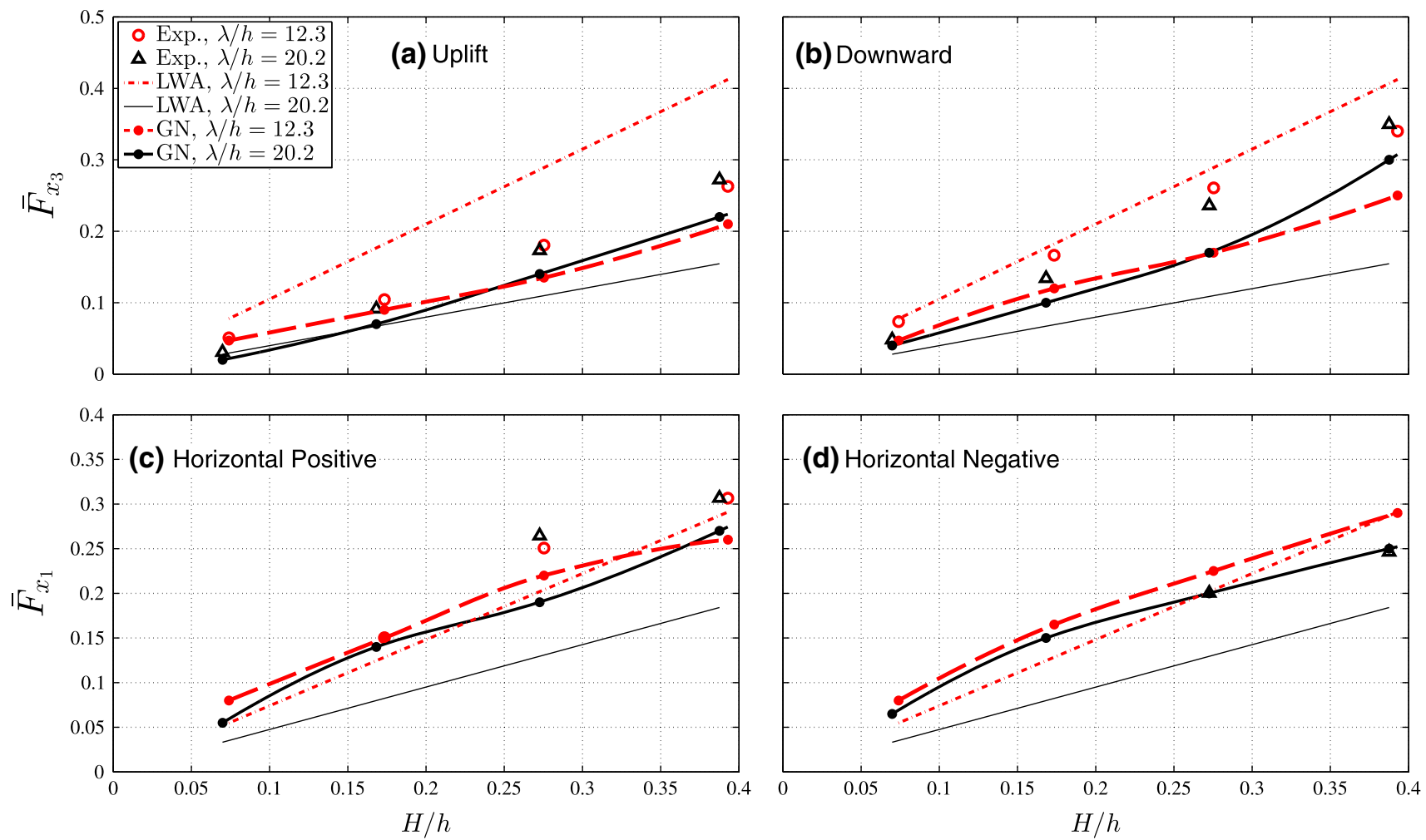

Fig. 21 Laboratory measurements and the GN and LWA calculations of a vertical uplift, $\mathbf{b}$ vertical downward, $\mathbf{c}$ horizontal positive and, $\mathbf{d}$ horizontal negative forces of cnoidal waves of different wave height and wavelengths propagating over a submerged plate $(h=0.114 \mathrm{~m}$ and $z / h=0.4)$
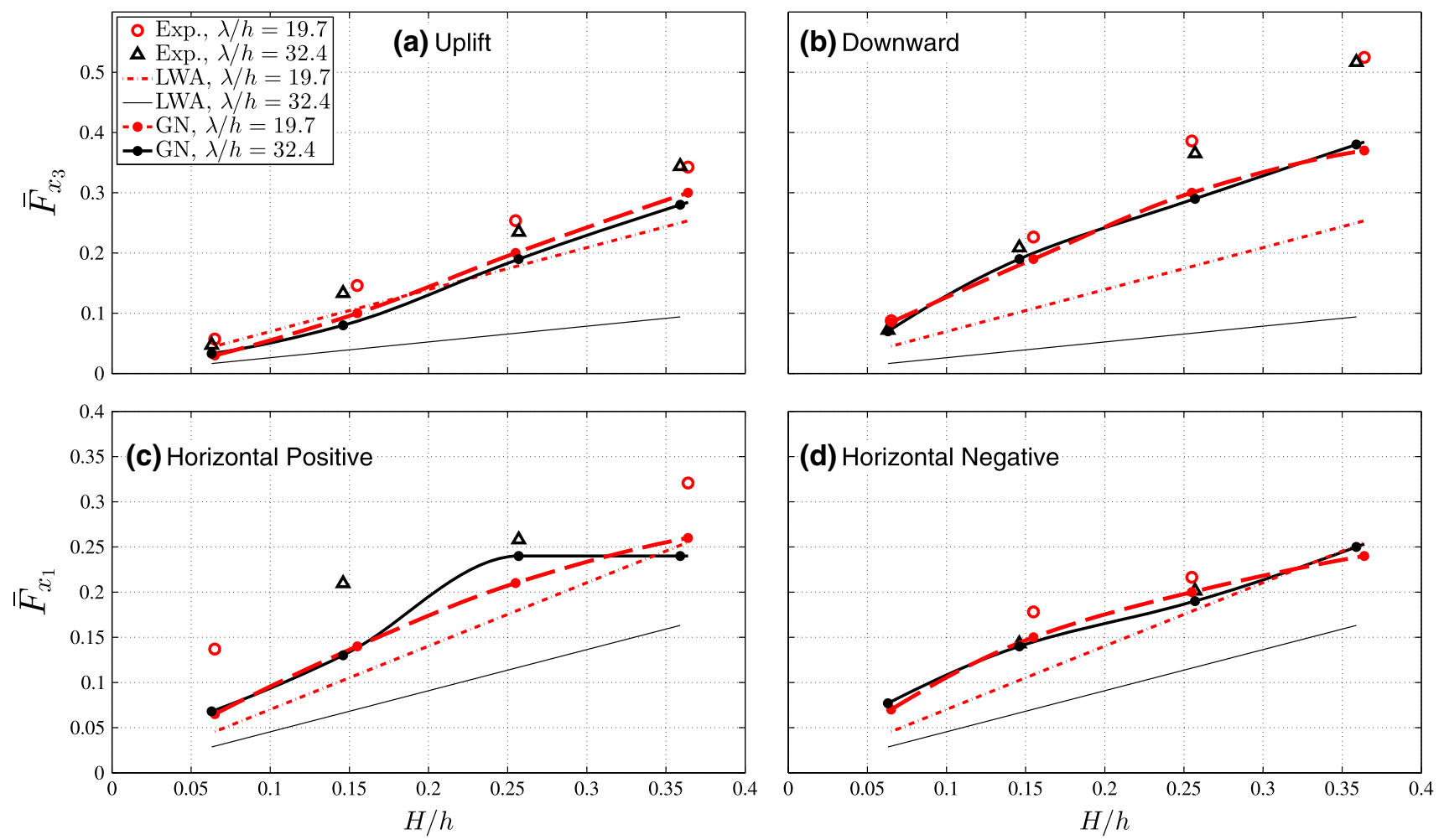

Fig. 22 Laboratory measurements and the GN and LWA calculations of a vertical uplift, $\mathbf{b}$ vertical downward, chorizontal positive and, $\mathbf{d}$ horizontal negative forces of cnoidal waves of different wave height and wavelengths propagating over a submerged plate $(h=0.071 \mathrm{~m}$, and $z / h=0.6)$ 

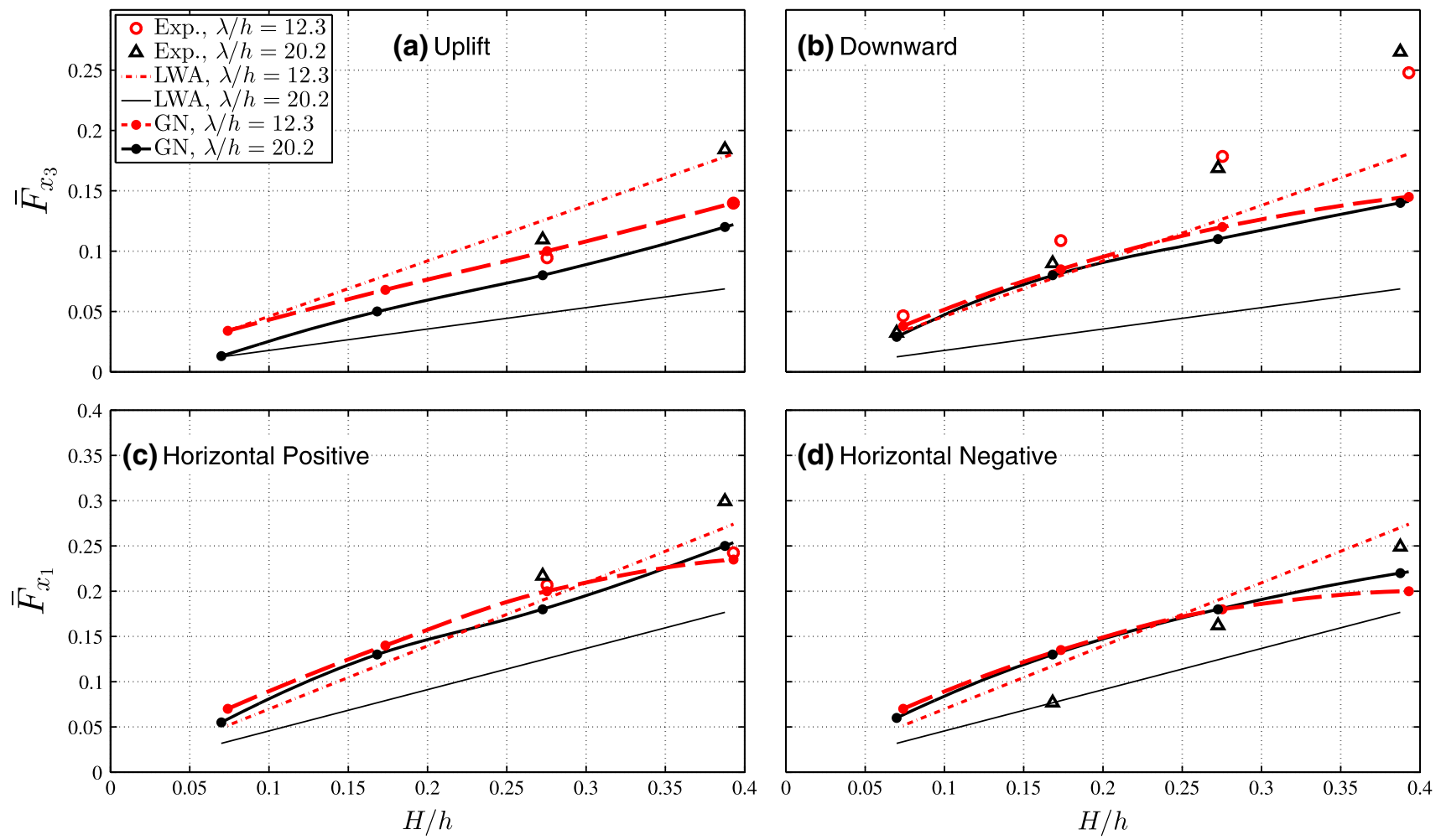

Fig. 23 Laboratory measurements and the GN and LWA calculations of a vertical uplift, $\mathbf{b}$ vertical downward, chorizontal positive and, $\mathbf{d}$ horizontal negative forces of cnoidal waves of different wave height and wavelengths propagating over a submerged plate $(h=0.114 \mathrm{~m}$, and $z / h=0.6)$

The least agreement is observed for $z / h=0.4$ and large wave heights, for which $H / z$ (ratio of wave height to water depth in the region above the plate) may become close to 1. Wave breaking is expected at such limits (if the plate was wide enough), and this is beyond the limits of the theoretical considerations in the GN equations.

It is of interest that almost in all of the fully submerged cases, even though the wave is nonlinear (and so is the waveinduced force), the vertical forces vary semi-linearly with the wave height, in both $z / h=0.4$ and $z / h=0.6$ cases. Such variation is observed in both calculations and the laboratory measurements. The horizontal forces, on the other hand, show some oscillations with the wave height, and such behavior appears to be a function of the submergence depth and wavelength. However, we should note that this dependence of wave force on the wave height is also a function of other parameters, such as the width, $B$, of the plate, and this has not been studied in this work.

\section{Summary and conclusions}

Laboratory measurements of cnoidal wave forces on a horizontal flat plate located in shallow-water are presented for a range of wave heights, wavelengths and two water depths. Based on the relative location of the plate to the SWL, sev- eral conditions are considered, including a fully elevated plate, a plate on the surface and a fully submerged plate. It is found that the vertical uplift force and horizontal positive force are largest when the plate is near the water surface, mainly due to the larger particle accelerations there. As expected, the vertical uplift and the horizontal positive forces increase with larger wave height in all cases. The data presented here can be used at the design stage or for vulnerability assessment of coastal bridges, jetties, docks and piers during a storm condition after scaling the results through the Froude scaling law. Note that wave breaking, which occurs in the cases that the plate is on or above the SWL, cannot always be scaled, see for example, Hughes (1993) and Bullock et al. (2001).

For a horizontal deck of a typical coastal bridge located in shallow-water under the action of long waves considered here, the $\lambda / B$ ratio $(4.6 \leq \lambda / B \leq 7.5$ here $)$ is such that the forces (particularly the vertical uplift force and the horizontal positive force) do not vary significantly with the change in wavelength. The forces approach a constant value as $\lambda$ increases, mainly because only one wave crest interacts with the flat plate at a given time. As such, the results presented here can be used in any long-wave conditions, where $\lambda / B \gg 1$. This is in agreement with the findings of Hayatdavoodi (2013) and Hayatdavoodi and Ertekin (2014a), in which cnoidal wave forces approach those of a solitary wave 
of the same height for large $\lambda$ values; it is known of course that the theoretical limit is infinite.

A good agreement between solutions of Euler's equations, by use of the OpenFOAM CFD program, and the laboratory experiments for all elevations and submergence depths is observed. This reveals that a two-dimensional inviscid model in OpenFOAM can be used to study the problem of nonlinear wave interaction with horizontal decks, and it provides relatively accurate results, even in the cases that involve wave breaking.

For a deck that is above the SWL, the existing empirical relations of Douglass et al. (2006) and McPherson (2008), although overestimating the forces, provide some satisfactory results when compared with the laboratory measurements. Considering the simplicity of these relations, they can be used to provide an initial estimate of the nonlinear wave loads on an elevated deck in shallow-water. Due to the absence of wave period or wavelength in these relations, however, special attention should be paid when applying the equations when $\lambda / B \approx 1$.

The Long-Wave Approximation (linear solution) for wave forces on a submerged plate appears to underestimate the wave forces when $\lambda / h>19$ roughly. The LWA results are in close agreement with laboratory measurements and other computational solutions when the wavelength is shorter and wave height is smaller, mainly due to the waves being more linear.

The nonlinear GN Level I equations developed by Hayatdavoodi and Ertekin (2014b) provide good agreement with the laboratory measurements of wave forces on a fully submerged plate, particularly when the plate is farther away from the surface and the $t_{\mathrm{p}} / h$ ratio is smaller.

Almost in all cases, the horizontal positive force measured in the laboratory experiments is slightly different (usually larger) than the OpenFOAM calculations shown in this work. Although the difference is not significant, it may be due to the small-scale experiments, which results in high sensitivity to structural vibrations in the model set up, as well as some three-dimensional effects that are not considered in the calculations. Viscosity and turbulent effects may also be other sources of some of the differences. We, however, do not expect viscosity to play any significant role in this problem except when waves break.

The vertical uplift force and horizontal positive force appear to vary almost linearly with the wave height in all cases, even though the wave is nonlinear. The vertical downward force and the horizontal negative force remain nonlinear with the wave height, as they are influenced by wave diffraction over the plate. As such, any change in the $B / h$ ratio would result in different vertical downward and horizontal negative forces. Failure of the structure, however, is known to occur mainly due to the vertical uplift force and horizontal positive force. Therefore, these two forces and understand- ing of their variations with the wave conditions should be of high interest.

Acknowledgments This work is partially based on funding from State of Hawaii's Department of Transportation (HDOT) and the Federal Highway Administration (FHWA) Research Branch, Grant Nos. DOT08-004, TA 2009-1R. The work of M.H. is also supported by the Link Foundation's Ocean Engineering and Instrumentation Fellowship provided to the University of Hawaii. Any findings and opinions contained in this paper are those of the authors and do not necessarily reflect the opinions of the funding agencies. The assistance of Prof. Ian Robertson and Mr. Mitch Pinkerton, of the University of Hawaii's Civil and Environmental Engineering Department, received during the course of the experiments, is greatly appreciated.

\section{References}

AASHTO (2008) Guide specifications for bridges vulnerable to coastal storms. American Association of State Highway and Transportation Officials

Baarholm R, Faltinsen OM (2004) Wave impact underneath horizontal decks. J Mar Sci Technol 9:1-13

Bea RG, Xu T, Stear J, Ramos R (1999) Wave forces on decks of offshore platforms. J Waterw Port Coast Ocean Eng 125(3):136-144

Bhat SS (1994) Wave slamming on a horizontal plate. Master's Thesis, University of British Columbia, Canada

Brater EF, McNown JS, Stair LD (1958) Wave forces on submerged structures. J Hydraul Div ASCE 84:1-26

Brossard J, Perret G, Blonce L, Diedhiou A (2009) Higher harmonics induced by a submerged horizontal plate and a submerged rectangular step in a wave flume. Coast Eng 56(1):11-22

Bullock GN, Crawford AR, Hewson PJ, Walkden MJA, Bird PAD (2001) The influence of air and scale on wave impact pressures. Coast Eng 42(4):291-312

Carter RW, Ertekin RC, Lin P (2006) On the reverse flow beneath a submerged plate due to wave action. In: OMAE2006 25th international conference on offshore mechanics and Arctic engineering. ASME, Hamburg, pp 595-602

Chen Q, Wang L, H Z (2009) Hydrodynamic investigation of coastal bridge collapse during hurricane katrina. J Hydraul Eng 135(3): 175-186

Denson KH (1978) Wave forces on causeway-type coastal bridges. Technical Report MS 39762. Water Resources Research Institute, Mississippi State University

Des Roches R (ed) (2006) Hurricane Katrina: performance of transportation systems. ASCE Technical Council on Lifeline Earthquake Engineering (TCLEE) Monograph No. 29, ASCE

Douglass SL, Chen Q, Olsen JM, Edge BL, Brown D (2006) Wave forces on bridge decks. Technical report, U.S. Department of Transportation, Office of Bridge Technology, Washington, DC

El Ghamry OA (1963) Wave forces on a dock. University of California, Berkeley, Hydraulic Engineering Laboratory, Institute of Engineering Research Technical Report

Ertekin RC (1984) Soliton generation by moving disturbances in shallow water: theory, computation and experiment. Ph.D. thesis, University of California at Berkeley

Ertekin RC, Becker JM (1998) Nonlinear diffraction of waves by a submerged shelf in shallow water. J Offshore Mech Arct Eng 120:212220

French JA (1969) wave uplift pressures on horizontal platforms. Tech. rep., W. M. Keck Laboratory of Hydraulics and Water Resources, Division of Engineering and Applied Science, California Institute of Technology, Report No. KH-R-19, Pasadena, California 
Goring DG (1979) Tsunamis - the propagation of long waves onto a shelf. Ph.D. thesis, California Institute of Technology, Pasadena

Green AE, Naghdi PM (1974) On the theory of water waves. Proc R Soc Lond Ser A Math Phys Sci 338(1612):43-55

Green AE, Naghdi PM (1976a) A derivation of equations for wave propagation in water of variable depth. J Fluid Mech 78:237-246

Green AE, Naghdi PM (1976b) Directed fluid sheets. Proc R Soc Lond Ser A Math Phys Sci 347(1651):447-473

Hayatdavoodi M (2013) Nonlinear wave loads on decks of coastal structures. Ph.D. thesis, University of Hawaii at Manoa, December

Hayatdavoodi M, Seiffert B, Ertekin RC (2014) Experiments and computations of solitary-wave forces on a coastal-bridge deck. Part II: deck with girders. Coast Eng 88(June):210-228. doi:10.1016/ j.coastaleng.2014.02.007

Hayatdavoodi M, Ertekin RC (2012) Nonlinear forces on a submerged, horizontal plate: the GN theory. In: 27th International workshop on water waves and floating bodies. Denmark, Copenhagen, pp $69-72$

Hayatdavoodi M, Ertekin RC (2014a) A comparative study of nonlinear shallow-water wave loads on a submerged horizontal box. In: Proceedings of 33rd internationalconference on ocean, offshore and Arctic engineering, OMAE '14. ASME, San Francisco, p 11

Hayatdavoodi M, Ertekin RC (2014b) Wave forces on a submerged horizontal plate. Part I: theory and modeling. J Fluids Struct (in press)

Hayatdavoodi M, Ertekin RC (2014c) Wave forces on a submerged horizontal plate. Part II: solitary and cnoidal waves. J Fluids Struct (in press)

Huang W, Xiao H (2009) Numerical modeling of dynamic wave force acting on escambia bay bridge deck during hurricane ivan. $\mathrm{J}$ Waterw Port Coast Ocean Eng 135(4):12

Hughes S (1993) Physical models and laboratory techniques in coastal engineering. In: Advanced series on ocean engineering, vol 7. World Scientific, Singapore

Isaacson M, Bhat S (1996) Wave forces on a horizontal plate. Int J Offshore Polar Eng 6(1):19-26

Jacobsen NG, Fuhrman DR, Fredsoe J (2012) A wave generation toolbox for the open-source CFD library: OpenFoam. Int J Numer Methods 70(9):1073-1088

Kaplan P, Murray JJ, Yu WC (1995) Theoretical analysis of wave impact forces on platform deck structures. Offshore mechanics and Arctic engineering. Denmark, ASME, Copenhagen, pp 189-198

Kim JW, Ertekin RC (2000) A numerical study of nonlinear wave interaction in irregular seas: irrotational Green-Naghdi model. Mar Struct 13:331-348

Kim JW, Bai KJ, Ertekin RC, Webster WC (2001) A derivation of the Green-Naghdi equations for irrotational flows. J Eng Math 40:1742

Liu C, Huang Z (2009) Nonlinear scattering of non-breaking waves by a submerged horizontal plate: experiments and simulations. Ocean Eng 36(17-18):1332-1345

Lo H, Liu PL (2014) Solitary waves incident on a submerged horizontal plate. J Waterw Port Coast Ocean Eng 140(May/June):04014009(1-17)

McConnell K, Allsop W, Cruickshank I (2004) Piers, jetties, and related structures exposed to waves: guidelines for hydraulic loadings, 1st edn. Thomas Telford Press, London
McPherson RL (2008) Hurricane induced wave and surge forces on bridge decks. Master's thesis, Texas A\&M University, College Station

Meng B (2008) Calculation of extreme wave loads on coastal highway bridges. Ph.D. Thesis, Texas A \& M University

Morison JR, O'Brien MP, Johnson JW, Schaaf SA (1950) The force exerted by surface piles. Pet Trans 189:149-154

Overbeek J, Klabbers IM (2001) Design of jetty decks for extreme vertical wave loads. Ports 01. ASCE, Virginia, pp 1-10

Padgett J, DesRoches R, Nielson B, Yashinsky M, Kwon OS, Burdette N, Tavera E (2008) Bridge damage and repair costs from hurricane katrina. J Bridge Eng 13(1):6-14

Patarapanich M (1984a) Forces and moment on a horizontal plate due to wave scattering. Coast Eng 8(3):279-301. doi:10.1016/ 0378-3839(84)90006-1

Patarapanich M (1984b) Maximum and zero reflection from submerged plate. J Waterw Port Coast Ocean Eng 110(2):171-181

Robertson IN, Yim S, Riggs HR, Young YL (2007) Coastal bridge performance during Hurricane Katrina. In: Proceedings of the international conference on structural engineering, mechanics and computation 24 April 2001. South Africa, Millpress, the Netherlands, South Africa, Cape Town, pp 1864-1870

Sarpkaya T, Isaacson M (1981) Mechanics of wave forces on offshore structures. Litton Educational Publishing Inc, Mississippi

Schumacher T, Higgins C, Bradner C, Cox D, Yim S (2008) Largescale wave flume experiments on highway bridge superstructures exposed to hurricane wave forces. In: The sixth national seismic conference on bridges and highways. Charleston, South Carolina, Paper 2A3-5

Seiffert B, Hayatdavoodi M, Ertekin RC (2014) Experiments and computations of solitary-wave forces on a coastal-bridge deck. Part I: flat plate. Coast Eng 88(June):194-209. doi:10.1016/j.coastaleng. 2014.01.005

Shih RWK, Anastasiou K (1992) A laboratory study of the waveinduced vertical loading on platform decks. In: Proceedings of the ICE-water maritime and energy, vol 96. pp 19-33

Siew PF, Hurley DG (1977) Long surface waves incident on a submerged horizontal plate. J Fluid Mech 83:141-151

Sun X (1991) Some theoretical and numerical studies on cnoidalwave-diffraction problems. Master's thesis, University of Hawaii at Manoa, Honolulu

Svendsen IA, Jonsson IG (1976) Hydrodynamics of coastal regions. Den Private Ingeniørfond, Technical University of Denmark

Tech Rep Version (2012) The open source CFD toolbox, user guide. 2(1): 1

Tirindelli M, Cuomo G, Allsop W, McConnell K (2002) Exposed jetties: Inconsistencies and gaps in design methods for wave-induced forces. In: Proceedings of the international conference on coastal engineering. ASCE, Wales, pp 1684-1696

Wang H (1970) Water wave pressure on horizontal plate. J Hydraul Div 96(10):1997-2016

Webster WC, Duan WY, Zhao BB (2011) Green-Naghdi theory, part A: Green-Naghdi (GN) equations for shallow water waves. J Mar Sci Appl 10(3):253-258

Zhao B, Duan W, Ertekin R (2014) Application of higher-level GN theory to some wave transformation problems. Coast Eng 83:177189. doi:10.1016/j.coastaleng.2013.10.010 